Supporting Information to

\title{
Near-Ultraviolet Circular Dichroism of Achiral Phenolic Termini Induced by Nonchromophoric Poly(L,L-lactide) and Poly(D,D-lactide)
}

Kai Kan, ${ }^{\dagger,+}$ Michiya Fujiki, ${ }^{\dagger, *}$ Mitsuru Akashi, ${ }^{\S,}{ }^{*}$ Hiroharu Ajiro ${ }^{\dagger, \neq,+,, *}$

$\dagger$ Graduate School of Materials Science and $¥$ Institute for Research Initiatives, Division for Research Strategy, Nara Institute of Science and Technology, 8916-5, Takayama-cho, Ikoma, Nara, 630-0192, Japan

E-mail: ajiro@ms.naist.jp; Fax: +81-743-72-5509; Tel: +81-743-72-5508,

E-mail; fujikim@ms.naist.jp; Fax: +81-743-72-6049; Tel: +81-743-72-6040

§Graduate School of Frontier Biosciences, Osaka University, 2-1 Yamada-oka, Suita, 565-0871, Japan

E-mail: akashi@fbs.osaka-u.ac.jp; Fax: +81-6-6878-9712; Tel: +81-6-6105-5247

${ }^{\perp}$ JST PRESTO, 4-1-8 Honcho, Kawaguchi, Saitama, 332-0012, Japan

Contents

page

1. Experimental procedure 2-6

2. ${ }^{1} \mathrm{H}$ NMR spectra of polymers $\quad 7-15$

3. CD and UV-vis spectra of polymers $\quad 16-26$

4. Simulation of potential surface energy of L-lactide-vanillin 27

5. PL of PLLA-vanillin and PDLA-vanillin 28

6. CPL of PLLA-vanillin and PDLA-vanillin 29 


\section{Experimental procedure}

\section{1-1. Materials}

L,L-lactide (LLA; Musashino Chemical Laboratory, Ltd., Japan) and D,D-lactide (DLA; Musashino Chemical Laboratory, Ltd., Japan) were recrystallized from ethyl acetate/ $n$-hexane and cooled in a freezer at $-20{ }^{\circ} \mathrm{C}$. Then the obtained crystal was filtered, and dried under vacuum at room temperature. Vanillin, ethyl vanilate, 3-ethoxy-4-hydroxybenzaldehyde (ethyl vanillin), syringaldehyde, 4-fluorophenol, 4-tertbutylphenol, guiacol, 4-amylphenol, and 4-chlorophenol were purchased from Tokyo Chemical Industry, Ltd., Japan. Methanol, chloroform, spectroscopic grade chloroform, 1-dodecanol, anhydrous toluene, and $\mathrm{CHCl}_{3}$ (chloroform, super dehydrated, amylene added) were purchased from Wako Pure Chemical Industries, Ltd., Japan. Vanillin, ethyl vanilate, ethyl vanillin, syringaldehyde, 4-fluorophenol, 4-tertbutylphenol, methanol, chloroform, tetrahydrofuran (THF), and spectroscopic grade chloroform were used without purification. Anhydrous toluene was also dried by $4 \AA$ molecular sieves (Nacalai tesque, Inc., Japan) under nitrogen atmosphere. Guiacol, 4-amylphenol. 4-chlorophenol, and 1-dodecanol were distilled from $4 \AA$ molecular sieves as a drying agent under nitrogen gas before use. Additionally $4 \AA$ molecular sieves was used under vacuum at $200{ }^{\circ} \mathrm{C}$ for $24 \mathrm{~h}$.

\section{1-2. Measurements}

The number average of molecular weight of PLA was determined by size exclusion chromatography (SEC). A JASCO Chem NAV system was used with polystyrene standards at $40{ }^{\circ} \mathrm{C}$, equipped with PU2080, AS-2055, CO-2065, and RI-2031. Two commercial columns (TSKgel SuperH4000 and TSKgel $\mathrm{GMH}_{\mathrm{XL}}$ ) were connected in series and THF was used as an eluent. ${ }^{1} \mathrm{H}$ NMR spectra were measured with a NMR spectrometer (JEOL ECA-600) at $600 \mathrm{MHz}$. CD/UV spectral measurements were conducted at 20 ${ }^{\circ} \mathrm{C}$ using a J-820 spectropolarimeter (JASCO, Tokyo, Japan) equipped with Peltier-controlled thermostat (PTC-423L) housing unit using a SQ-grade cuvette, with a path length of $10 \mathrm{~mm}$, PMT response of slow mode, a scanning rate of $50 \mathrm{~nm} \mathrm{m^{-1 }}$, bandwidth of $4 \mathrm{~nm}, 1 \mathrm{~nm}$ interval data sampling, and a single accumulation. Fluorescent spectra were measured on a JASCO FP-6600 spectrofluorometer under a scanning rate of $50 \mathrm{~nm} \mathrm{~min}^{-1}$, bandwidths of $10 \mathrm{~nm}$ (excitation) and 5nm (emission) for PL measurement, bandwidths of $5 \mathrm{~nm}$ (excitation) and $10 \mathrm{~nm}$ (emission) for PLE measurement, response time of $2 \mathrm{~s}$, PMT gain high, and $0.5 \mathrm{~nm}$ interval data sampling at $20{ }^{\circ} \mathrm{C}$. CPL/PL spectra were measured at $20{ }^{\circ} \mathrm{C}$ using a JASCO CPL-200 spectrofluoropolarimeter (JASCO, Tokyo, Japan) equipped with a Peltier-controlled housing using the SQ-grade quartz cuvette under a single accumulation, a path length of $10 \mathrm{~mm}$, a bandwidth for excitation of $3000 \mu \mathrm{m}$, a bandwidth for CPL measurement of $3000 \mu \mathrm{m}$, a scanning rate of $50 \mathrm{~nm} \mathrm{~min}-1,1 \mathrm{~nm}$ interval data sampling, a response time of $8 \mathrm{~s}$, and $280 \mathrm{~nm}$ excitation wavelength. 
1-3. Synthesis of poly(L,L-lactide)-vanillin (PLLA-vanillin) (1) and poly(D,D-lactide)-vanillin (PDLA-vanillin) (2)

To the round bottom flask, LLA $(1.0 \mathrm{~g}, 6.9 \mathrm{mmol})$ and vanillin $(0.053 \mathrm{~g}, 0.35 \mathrm{mmol})$ were dried under vacuum, and purged with nitrogen for three times. Then $2.2 \mathrm{ml}$ of $1 \mathrm{vol} \% \operatorname{SnOct}_{2}(69 \mu \mathrm{mol})$ in dry toluene solution was combined to heat up at $120{ }^{\circ} \mathrm{C}$ for $2 \mathrm{hr}$ under nitrogen atmosphere. After the reaction, the product was dissolved in chloroform and purified by re-precipitation over methanol three times. PDLAvanillin was synthesized in a similar way as PLLA-vanillin. By changing the molar ratio of the vanillin initiator against the LLA monomer and DLA monomer, the three molecular weights of PLLA-vanillin were obtained (1, 1a, 1b, 2, 2a, and 2b listed in Table S1). 1 (Yield: 89\%, $M_{\mathrm{n}}=11400 \mathrm{gmol}^{-1}, M_{\mathrm{w}} / M_{\mathrm{n}}=$ 1.97). 1a (Yield: $58 \%, M_{\mathrm{n}}=8600 \mathrm{gmol}^{-1}, M_{\mathrm{w}} / M_{\mathrm{n}}=1.51$ ). 1b (Yield: $41 \%, M_{\mathrm{n}}=3600 \mathrm{gmol}^{-1}, M_{\mathrm{w}} / M_{\mathrm{n}}=$ 1.64). 2 (Yield: $88 \%, M_{\mathrm{n}}=16800 \mathrm{gmol}^{-1}, M_{\mathrm{w}} / M_{\mathrm{n}}=1.95$ ). 2 a (Yield: $61 \%, M_{\mathrm{n}}=10400 \mathrm{gmol}^{-1}, M_{\mathrm{w}} / M_{\mathrm{n}}$ $=1.51$ ). 2 b (Yield: $41 \%, M_{\mathrm{n}}=4000 \mathrm{gmol}^{-1}, M_{\mathrm{w}} / M_{\mathrm{n}}=1.55$ ).

\section{1-4. Synthesis of poly(L,L-lactide)-guiacol (PLLA-guiacol) (3) and poly(D,D-lactide)-guiacol (PDLA-guiacol) (4)}

To the round bottom flask, LLA $(1.0 \mathrm{~g}, 6.9 \mathrm{mmol})$ was dried under vacuum, and purged with nitrogen for three times. Then guiacol $(0.038 \mathrm{ml}, 0.35 \mathrm{mmol}), 2.2 \mathrm{ml}$ of $1 \mathrm{vol} \% \operatorname{SnOct}_{2}(69 \mu \mathrm{mol})$ in dry toluene solution were combined to heat up at $120^{\circ} \mathrm{C}$ for $2 \mathrm{hr}$ under nitrogen atmosphere. After the reaction, the product was dissolved in chloroform and purified by re-precipitation over methanol three times. PDLAguiacol was synthesized in a similar way as PLLA-guiacol. 3 (Yield: $91 \%, M_{\mathrm{n}}=12900 \mathrm{gmol}^{-1}, M_{\mathrm{w}} / M_{\mathrm{n}}=$ 1.6). 4 (Yield: $91 \%, M_{\mathrm{n}}=10900 \mathrm{gmol}^{-1}, M_{\mathrm{w}} / M_{\mathrm{n}}=1.63$ ).

\section{1-5. Synthesis of poly(L,L-lactide)-ethyl vanilate (PLLA-ethyl vanilate) (5) and poly(D,D-lactide)- ethyl vanilate (PDLA-ethyl vanilate) (6)}

To the round bottom flask, LLA $(1.0 \mathrm{~g}, 6.9 \mathrm{mmol})$ and ethyl vanilate $(0.068 \mathrm{~g}, 0.35 \mathrm{mmol})$ were dried under vacuum, and purged with nitrogen for three times. Then $2.2 \mathrm{ml}$ of 1 vol\% SnOct $_{2}(69 \mu \mathrm{mol})$ in dry toluene solution was combined to heat up at $120^{\circ} \mathrm{C}$ for $2 \mathrm{hr}$ under nitrogen atmosphere. After the reaction, the product was dissolved in chloroform and purified by re-precipitation over methanol three times. PDLA-ethyl vanilate was synthesized in a similar way as PLLA-ethyl vanilate. 5 (Yield: 80\%, $M_{\mathrm{n}}=18500$ $\left.\mathrm{gmol}^{-1}, M_{\mathrm{w}} / M_{\mathrm{n}}=1.71\right) .6$ (Yield: $82 \%, M_{\mathrm{n}}=17200 \mathrm{gmol}^{-1}, M_{\mathrm{w}} / M_{\mathrm{n}}=1.74$ ). 
1-6. Synthesis of poly(L,L-lactide)-ethyl vanillin (PLLA-ethyl vanillin) (7) and poly(D,D-lactide)ethyl vanillin (PDLA-ethyl vanillin) (8)

To the round bottom flask, LLA $(1.0 \mathrm{~g}, 6.9 \mathrm{mmol})$ and ethyl vanillin $(0.058 \mathrm{~g}, 0.35 \mathrm{mmol})$ were dried under vacuum, and purged with nitrogen for three times. Then $2.2 \mathrm{ml}$ of 1 vol\% SnOct $_{2}(69 \mu \mathrm{mol})$ in dry toluene solution was combined to heat up at $120^{\circ} \mathrm{C}$ for $2 \mathrm{hr}$ under nitrogen atmosphere. After the reaction, the product was dissolved in chloroform and purified by re-precipitation over methanol three times. PDLA-ethyl vanillin was synthesized in a similar way as PLLA-ethyl vanillin. 7 (Yield: 91\%, $M_{\mathrm{n}}=26000$ $\mathrm{gmol}^{-1}, M_{\mathrm{w}} / M_{\mathrm{n}}=1.55$ ). 8 (Yield: $92 \%, M_{\mathrm{n}}=25300 \mathrm{gmol}^{-1}, M_{\mathrm{w}} / M_{\mathrm{n}}=1.52$ ).

1-7. Synthesis of poly(L,L-lactide)-syringaldehyde (PLLA-syringaldehyde) (9) and poly(D,Dlactide)-syringaldehyde (PDLA-syringaldehyde) (10)

To the round bottom flask, LLA $(1.0 \mathrm{~g}, 6.9 \mathrm{mmol})$ and syringaldehyde $(0.063 \mathrm{~g}, 0.35 \mathrm{mmol})$ were dried under vacuum, and purged with nitrogen for three times. Then $2.2 \mathrm{ml}$ of 1 vol\% SnOct $_{2}(69 \mu \mathrm{mol})$ in dry toluene solution was combined to heat up at $120^{\circ} \mathrm{C}$ for $2 \mathrm{hr}$ under nitrogen atmosphere. After the reaction, the product was dissolved in chloroform and purified by re-precipitation over methanol three times. PDLA-syringaldehyde was synthesized in a similar way as PLLA-syringaldehyde. 9 (Yield: $16 \%, M_{\mathrm{n}}=$ $\left.7600 \mathrm{gmol}^{-1}, M_{\mathrm{w}} / M_{\mathrm{n}}=1.24\right) .10$ (Yield: $16 \%, M_{\mathrm{n}}=7500 \mathrm{gmol}^{-1}, M_{\mathrm{w}} / M_{\mathrm{n}}=1.25$ ).

1-8. Synthesis of poly(L,L-lactide)-4-tert-butylphenol (PLLA-4-tert-butylphenol) (11) and poly(D,Dlactide)-4-tert-butylphenol (PDLA-4-tert-butylphenol) (12)

To the round bottom flask, LLA $(1.0 \mathrm{~g}, 6.9 \mathrm{mmol})$ and 4-tert-butylphenol $(0.052 \mathrm{~g}, 0.35 \mathrm{mmol})$ were dried under vacuum, and purged with nitrogen for three times. Then $2.2 \mathrm{ml}$ of 1 vol\% SnOct $_{2}(69 \mu \mathrm{mol})$ in dry toluene solution was combined to heat up at $120^{\circ} \mathrm{C}$ for $2 \mathrm{hr}$ under nitrogen atmosphere. After the reaction, the product was dissolved in chloroform and purified by re-precipitation over methanol three times. PDLA-4-tert-butylphenol was synthesized in a similar way as PLLA-4-tert-butylphenol. 11 (Yield: $87 \%, M_{\mathrm{n}}=9200 \mathrm{gmol}^{-1}, M_{\mathrm{w}} / M_{\mathrm{n}}=1.73$ ). 12 (Yield: $\left.88 \%, M_{\mathrm{n}}=9200 \mathrm{gmol}^{-1}, M_{\mathrm{w}} / M_{\mathrm{n}}=1.7\right)$.

1-9. Synthesis of poly(L,L-lactide)-4-amylphenol (PLLA-4-amylphenol) (13) and poly(D,D-lactide)4-amylphenol (PDLA-4-amylphenol) (14)

To the round bottom flask, LLA $(1.0 \mathrm{~g}, 6.9 \mathrm{mmol})$ was dried under vacuum, and purged with nitrogen for three times. Then 4-amylphenol $(0.059 \mathrm{ml}, 0.35 \mathrm{mmol}), 2.2 \mathrm{ml}$ of 1 vol\% SnOct $_{2}(69 \mu \mathrm{mol})$ in dry toluene solution were combined to heat up at $120{ }^{\circ} \mathrm{C}$ for $2 \mathrm{hr}$ under nitrogen atmosphere. After the reaction, the product was dissolved in chloroform and purified by re-precipitation over methanol three times. 
PDLA-4-amylphenol was synthesized in a similar way as PLLA-4-amylphenol. 13 (Yield: 90\%, $M_{\mathrm{n}}=9900$ gmol $^{-1}, M_{\mathrm{w}} / M_{\mathrm{n}}=1.64$ ). 14 (Yield: $90 \%, M_{\mathrm{n}}=8200 \mathrm{gmol}^{-1}, M_{\mathrm{w}} / M_{\mathrm{n}}=1.71$ ).

1-10. Synthesis of poly(L,L-lactide)-4-chlorophenol (PLLA-4-chlorophenol) (15) and poly(D,Dlactide)-4-chlorophenol (PDLA-4-chlorophenol) (16)

To the round bottom flask, LLA $(1.0 \mathrm{~g}, 6.9 \mathrm{mmol})$ was dried under vacuum, and purged with nitrogen for three times. Then 4-chlorophenol $(0.034 \mathrm{ml}, 0.35 \mathrm{mmol}), 2.2 \mathrm{ml}$ of $1 \mathrm{vol} \% \mathrm{SnOct}_{2}(69 \mu \mathrm{mol})$ in dry toluene solution were combined to heat up at $120{ }^{\circ} \mathrm{C}$ for $2 \mathrm{hr}$ under nitrogen atmosphere. After the reaction, the product was dissolved in chloroform and purified by re-precipitation over methanol three times. PDLA-4-chlorophenol was synthesized in a similar way as PLLA-4-chlorophenol. 15 (Yield: 90\%, $M_{\mathrm{n}}=$ 13,500 $\mathrm{g} \mathrm{mol}^{-1}, M_{\mathrm{w}} / M_{\mathrm{n}}=1.72$ ). 16 (Yield: $\left.86 \%, M_{\mathrm{n}}=13,900 \mathrm{~g} \mathrm{~mol}^{-1}, M_{\mathrm{w}} / M_{\mathrm{n}}=1.78\right)$.

1-11. Synthesis of poly(L,L-lactide)-4-fluorophenol (PLLA-4-fluorophenol) (17) and poly(D,Dlactide)-4-fluorophenol (PDLA-4-fluorophenol) (18)

To the round bottom flask, LLA (1.0 g, $6.9 \mathrm{mmol})$ and 4-fluorophenol $(0.039 \mathrm{~g}, 0.35 \mathrm{mmol})$ were dried under vacuum, and purged with nitrogen for three times. Then $2.2 \mathrm{ml}$ of 1 vol\% SnOct $_{2}(69 \mu \mathrm{mol})$ in dry toluene solution were combined to heat up at $120^{\circ} \mathrm{C}$ for $2 \mathrm{hr}$ under nitrogen atmosphere. After the reaction, the product was dissolved in chloroform and purified by re-precipitation over methanol three times. PDLA-4-fluorophenol was synthesized in a similar way as PLLA-4-fluorophenol. 17 (Yield: 86\%, $M_{\mathrm{n}}=$ 12,200 $\mathrm{g} \mathrm{mol}^{-1}, M_{\mathrm{w}} / M_{\mathrm{n}}=1.71$ ). 18 (Yield: $87 \%, M_{\mathrm{n}}=11,700 \mathrm{gmol}^{-1}, M_{\mathrm{w}} / M_{\mathrm{n}}=1.74$ ).

1-12. Synthesis of poly(L,L-lactide)-1-dodecanol (PLLA-1-dodecanol) (19) and poly(D,D-lactide)-1dodecanol (PDLA-1-dodecanol) (20)

PLLA-1-dodecanol and PDLA-1-dodecanol were prepared according to the literature. ${ }^{[\mathrm{S} 1]}$ The typical procedure is as follows. To the round bottom flask, LLA (1.0 g, $6.9 \mathrm{mmol})$ was dried under vacuum, and purged with nitrogen for three times. Then $1.1 \mathrm{ml}$ of $1 \mathrm{vol} \% 1$-dodecanol $(50 \mu \mathrm{mol})$ in dry toluene solution, $0.32 \mathrm{ml}$ of $1 \mathrm{vol} \% \operatorname{SnOct}_{2}(99 \mu \mathrm{mol})$ in dry toluene solution were combined to heat up at $120{ }^{\circ} \mathrm{C}$ for $3 \mathrm{hr}$ under nitrogen atmosphere. After the reaction, the product was dissolved in chloroform and purified by re-precipitation over methanol three times. PDLA-1-dodecanol was synthesized in a similar way as PLLA1-dodecanol. 19 (Yield: 82\%, $M_{\mathrm{n}}=17,600 \mathrm{~g} \mathrm{~mol}^{-1}, M_{\mathrm{w}} / M_{\mathrm{n}}=1.46$ ). 20 (Yield: 85\%, $M_{\mathrm{n}}=16,800 \mathrm{~g} \mathrm{~mol}^{-1}$, $\left.M_{\mathrm{w}} / M_{\mathrm{n}}=1.47\right)$. 
Table S1. Results of Polymerization and $g_{\mathrm{CD}}$ Value of PLLA and PDLA Derivatives

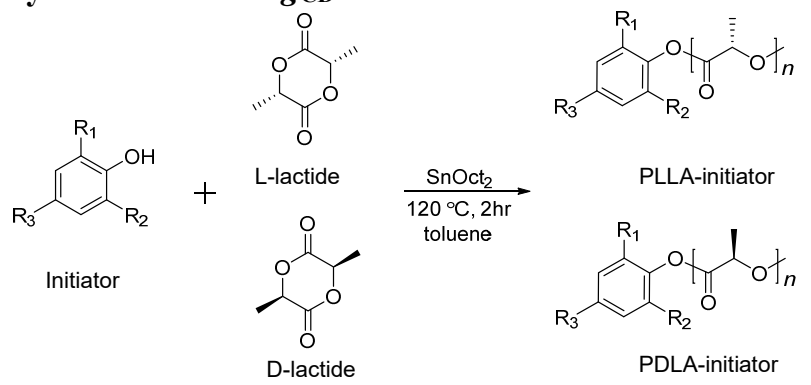

\begin{tabular}{cccccc}
\hline Entry & Polymers & $\mathrm{R}_{1}$ & $\mathrm{R}_{2}$ & $\mathrm{R}_{3}$ & $g_{\mathrm{CD}}$ (wavelength/nm) \\
\hline 1 & PLLA-4-tert-butylphenol (11) & $\mathrm{H}$ & $\mathrm{H}$ & $\mathrm{CH}\left(\mathrm{CH}_{3}\right)_{3}$ & - \\
2 & PDLA-4-tert-butylphenol (12) & $\mathrm{H}$ & $\mathrm{H}$ & $\left.\mathrm{CH}_{(\mathrm{CH}}\right)_{3}$ & - \\
3 & PLLA-4-amylphenol (13) & $\mathrm{H}$ & $\mathrm{H}$ & $\left(\mathrm{CH}_{2}\right)_{4} \mathrm{CH}_{3}$ & - \\
4 & PDLA-4-amylphenol (14) & $\mathrm{H}$ & $\mathrm{H}$ & $\left(\mathrm{CH}_{2}\right)_{4} \mathrm{CH}_{3}$ & - \\
5 & PLLA-4-chlorophenol (15) & $\mathrm{H}$ & $\mathrm{H}$ & $\mathrm{Cl}$ & - \\
6 & PDLA-4-chlorophenol (16) & $\mathrm{H}$ & $\mathrm{H}$ & $\mathrm{Cl}$ & - \\
7 & PLLA-4-fluorophenol (17) & $\mathrm{H}$ & $\mathrm{H}$ & $\mathrm{F}$ & - \\
8 & PDLA-4-fluorophenol (18) & $\mathrm{H}$ & $\mathrm{H}$ & $\mathrm{F}$ & - \\
\hline
\end{tabular}

\section{1-13. CD and UV-vis measurement of polymers}

All polymers 1-20 were dissolved in chloroform (r.t.) at concentrations of $0.050 \mathrm{~mol} \mathrm{~L}^{-1}(\mathbf{1}, \mathbf{1 a}, \mathbf{2}, \mathbf{5 - 8}$, 11-20), $0.025 \mathrm{~mol} \mathrm{~L}^{-1}(\mathbf{2 a}, \mathbf{3}, \mathbf{4}, \mathbf{9}, \mathbf{1 0}), 0.063 \mathrm{~mol} \mathrm{~L}^{-1}(\mathbf{1 b}, \mathbf{2 b})$, as lactide repeating unit, respectively.

\section{1-14. PL measurement of polymers}

PLLA-vanillin (1) and PDLA-vanillin (2) were dissolved in chloroform, super dehydrated, amylene added (r.t.) at concentrations of $0.020 \mathrm{~mol} \mathrm{~L}^{-1}$, respectively.

\section{1-15. CPL measurement of polymers}

PLLA-vanillin (1) and PDLA-vanillin (2) were dissolved in chloroform, super dehydrated, amylene added (r.t.) at concentrations of $0.10 \mathrm{~mol} \mathrm{~L}^{-1}$, respectively.

\section{1-16. Gaussian09, Revision E.01 Calculation.}

Potential surface energy calculation of lactide-vanillin was performed using Gaussian09, Rev.E.01 program $^{\text {S1 }}$ running on an Apple MacPro2008 (8-Cores, 2.66GHz, 32 GB memory, MacOS ver.1.75). The geometries of lactide-vanillin were optimized by the PM3-MM followed by DFT (B3LYP, 6-311G(d)) calculations as a function of dihedral angles of $\mathrm{L}, \mathrm{L}$-lactide and vanillin aromatic rings $\left(\mathrm{C}_{1}-\mathrm{C}_{2}-\mathrm{O}_{3}-\mathrm{C}_{4}\right)$ varying from $-80^{\circ}$ to $+80^{\circ}$ with $15^{\circ}$ interval. Simulated $\mathrm{CD}$ and UV-vis spectra of lactide-vanillin conformers were obtained using the TD-DFT (B3LYP, 6-31G(d) basis set) protocol with a half-width-athalf-height of $0.15 \mathrm{eV}$. 


\section{2. ${ }^{1} \mathrm{H}$ NMR spectra of polymers}

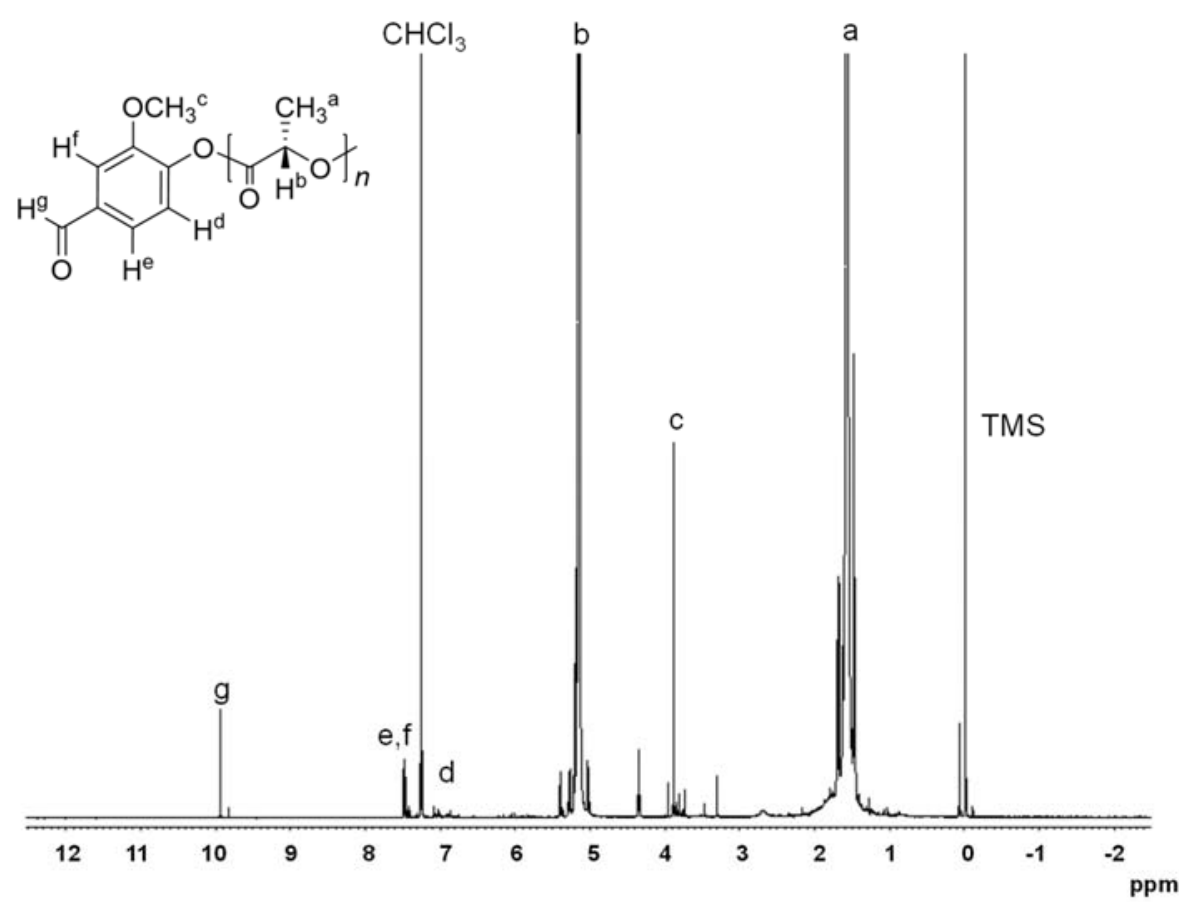

Figure S1. ${ }^{1} \mathrm{H}$ NMR spectrum of PLLA-vanillin (1) in $\mathrm{CDCl}_{3}(600 \mathrm{MHz})$.

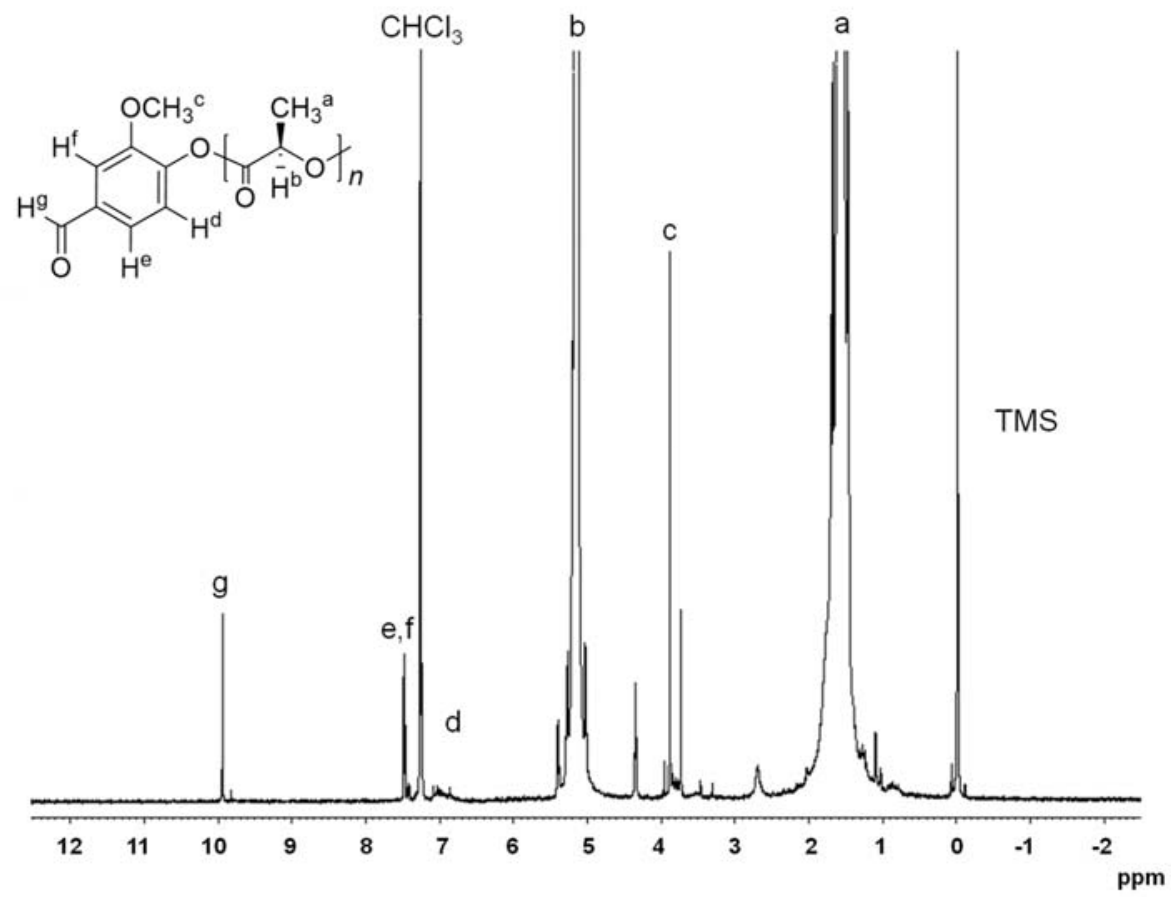

Figure S2. ${ }^{1} \mathrm{H}$ NMR spectrum of PDLA-vanillin (2) in $\mathrm{CDCl}_{3}(600 \mathrm{MHz})$. 


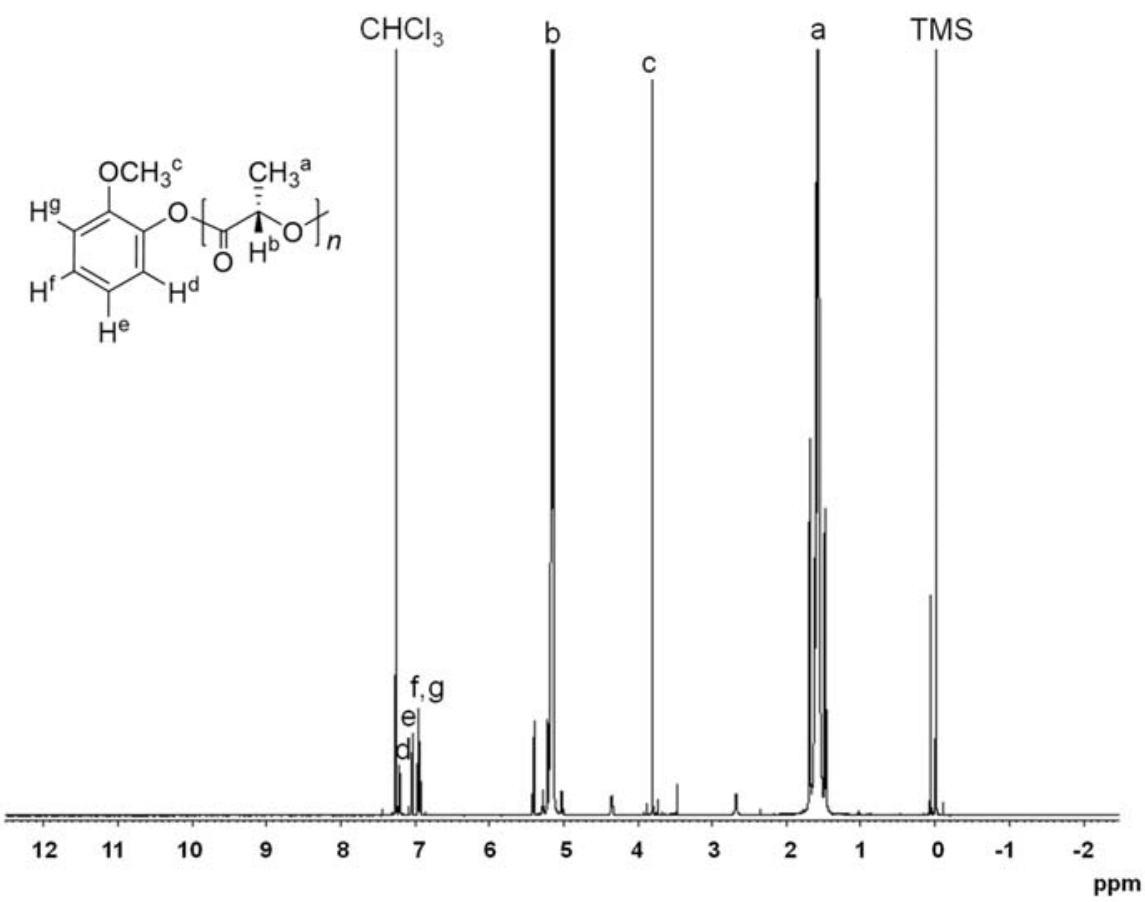

Figure S3. ${ }^{1} \mathrm{H}$ NMR spectrum of PLLA-guiacol (3) in $\mathrm{CDCl}_{3}(600 \mathrm{MHz})$.

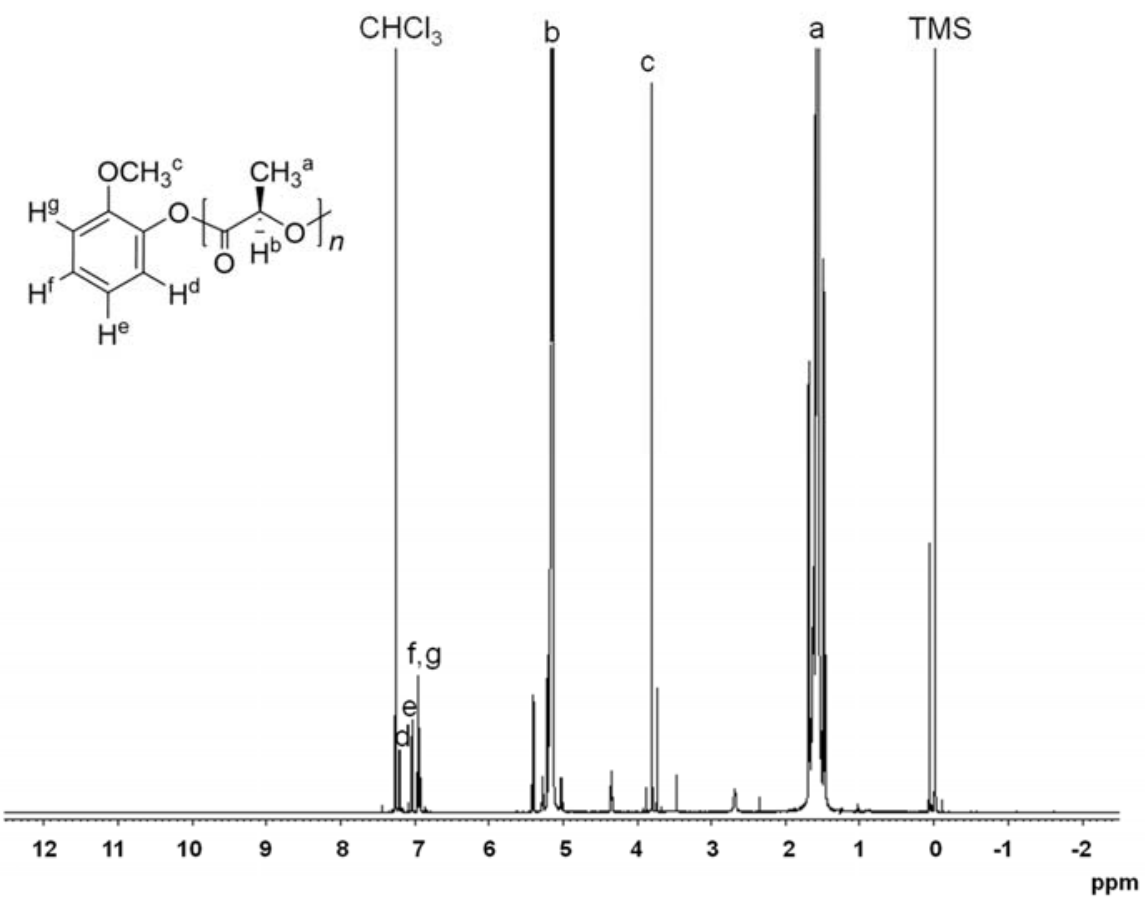

Figure S4. ${ }^{1} \mathrm{H}$ NMR spectrum of PDLA-guiacol (4) in $\mathrm{CDCl}_{3}(600 \mathrm{MHz})$. 


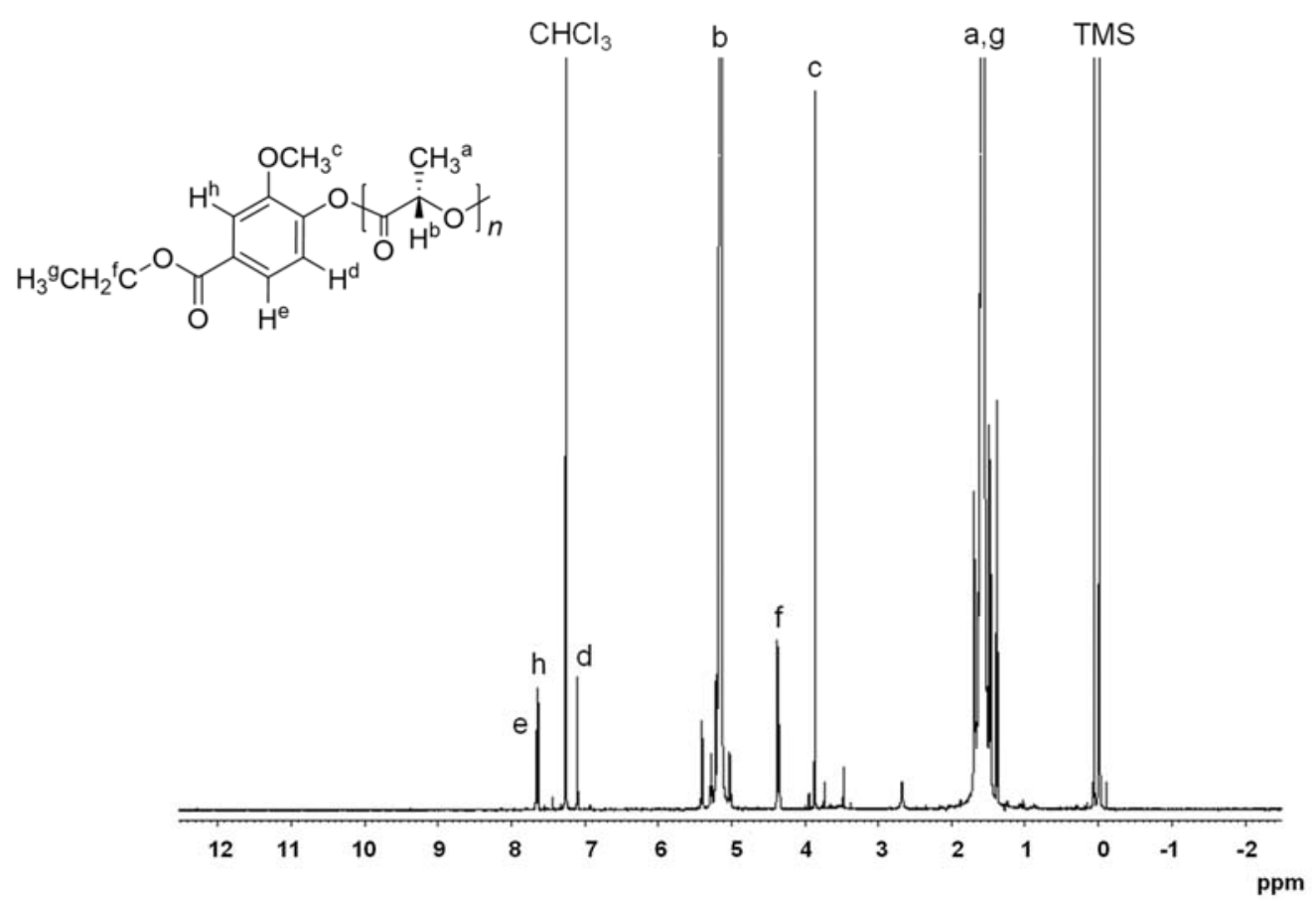

Figure S5. ${ }^{1} \mathrm{H}$ NMR spectrum of PLLA-ethyl vanilate (5) in $\mathrm{CDCl}_{3}(600 \mathrm{MHz})$.

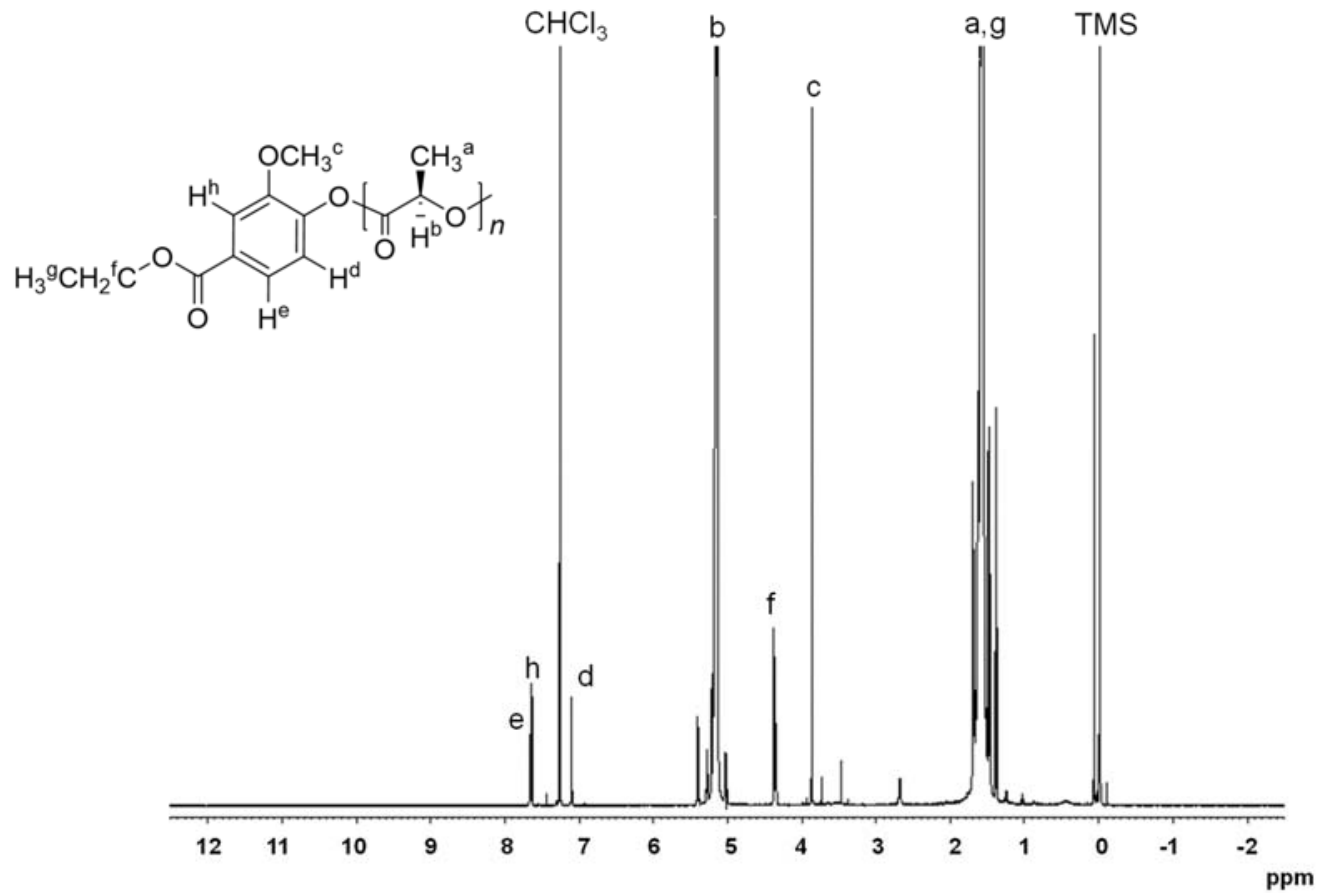

Figure S6. ${ }^{1} \mathrm{H}$ NMR spectrum of PDLA-ethyl vanilate (6) in $\mathrm{CDCl}_{3}(600 \mathrm{MHz})$. 


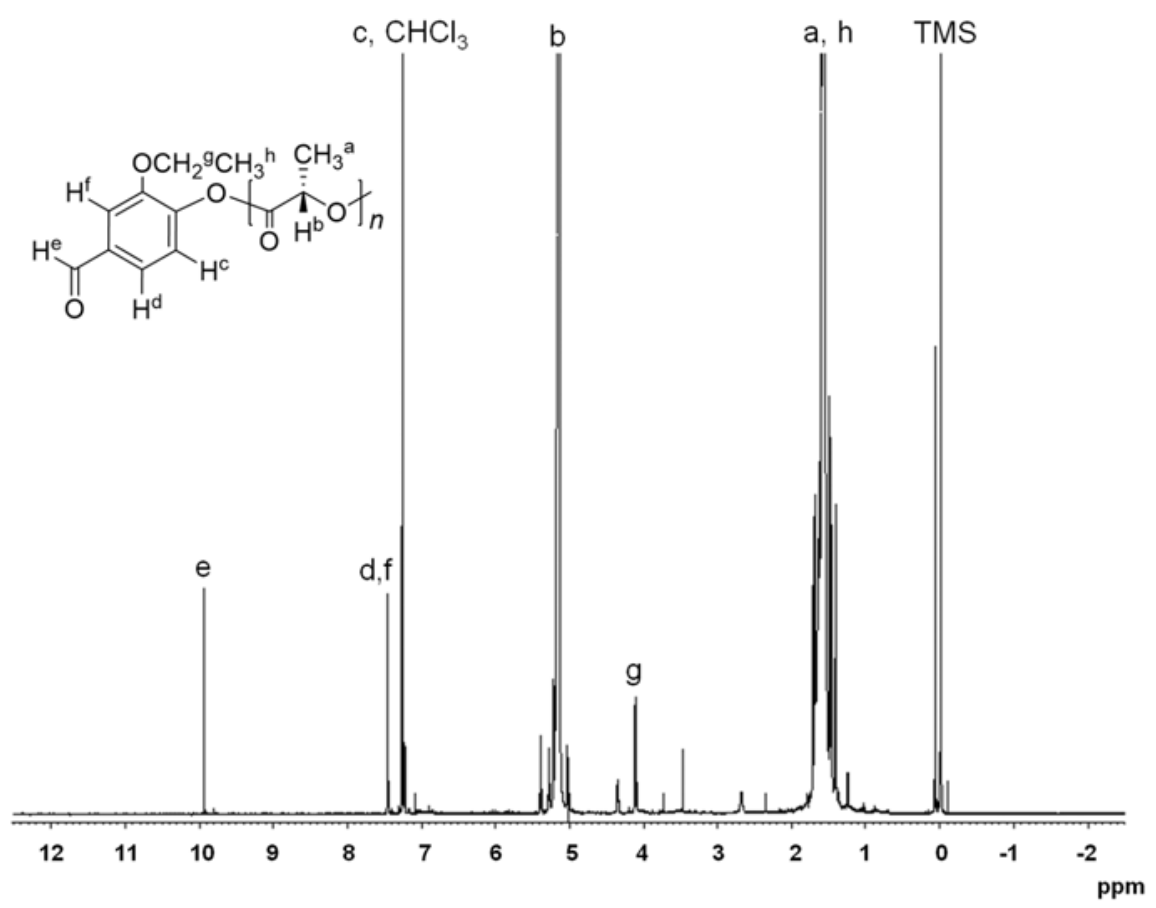

Figure S7. ${ }^{1} \mathrm{H}$ NMR spectrum of PLLA-ethyl vanillin (7) in $\mathrm{CDCl}_{3}(600 \mathrm{MHz})$.

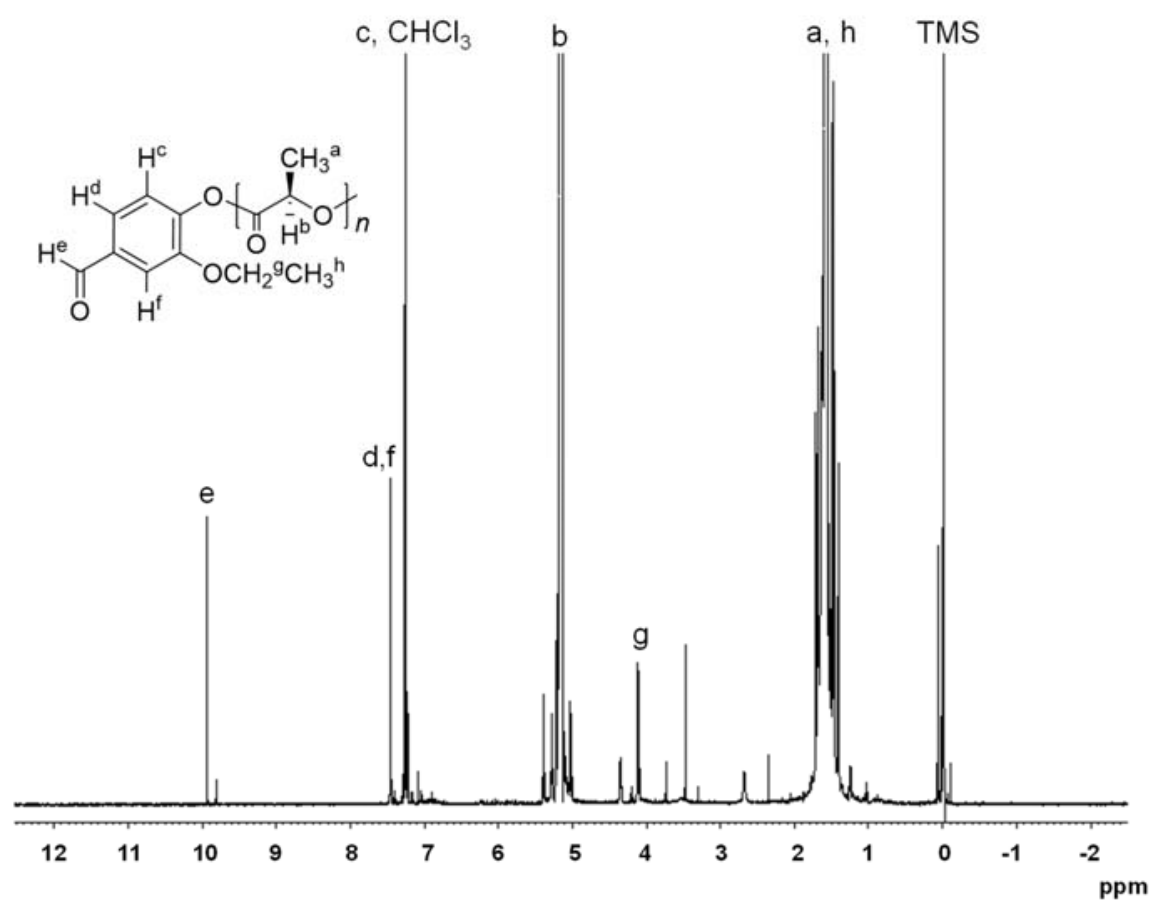

Figure S8. ${ }^{1} \mathrm{H}$ NMR spectrum of PDLA-ethyl vanillin (8) in $\mathrm{CDCl}_{3}(600 \mathrm{MHz})$. 


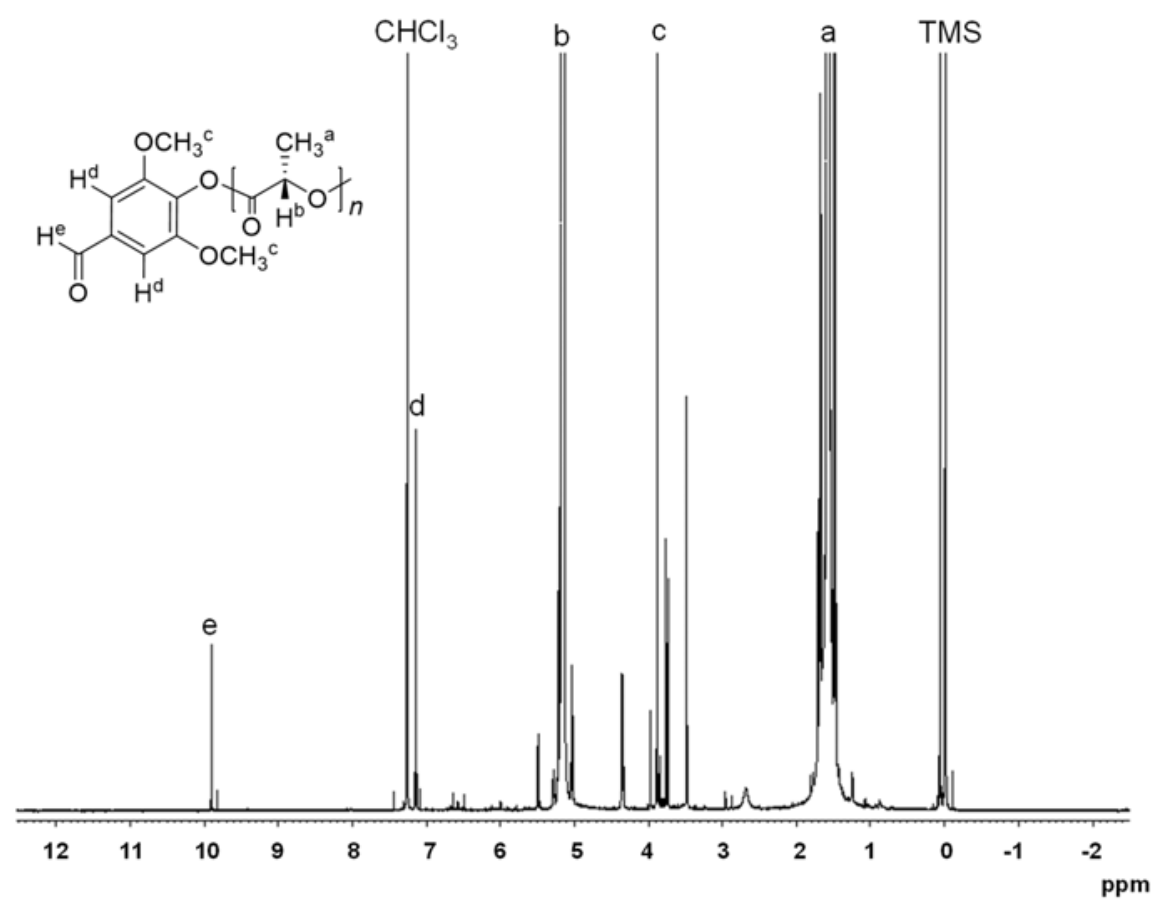

Figure S9. ${ }^{1} \mathrm{H}$ NMR spectrum of PLLA-syringaldehyde (9) in $\mathrm{CDCl}_{3}(600 \mathrm{MHz})$.

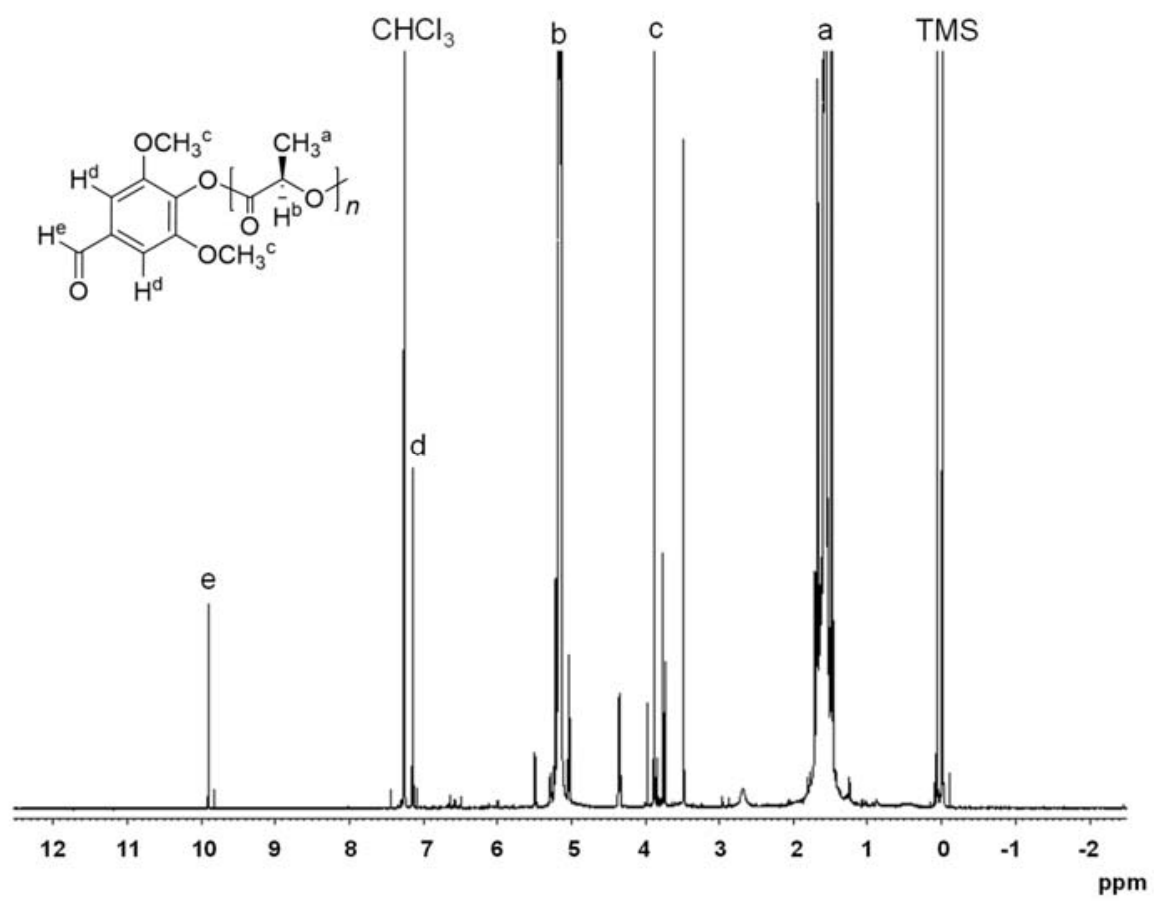

Figure S10. ${ }^{1} \mathrm{H}$ NMR spectrum of PDLA-syringaldehyde (10) in $\mathrm{CDCl}_{3}(600 \mathrm{MHz})$. 


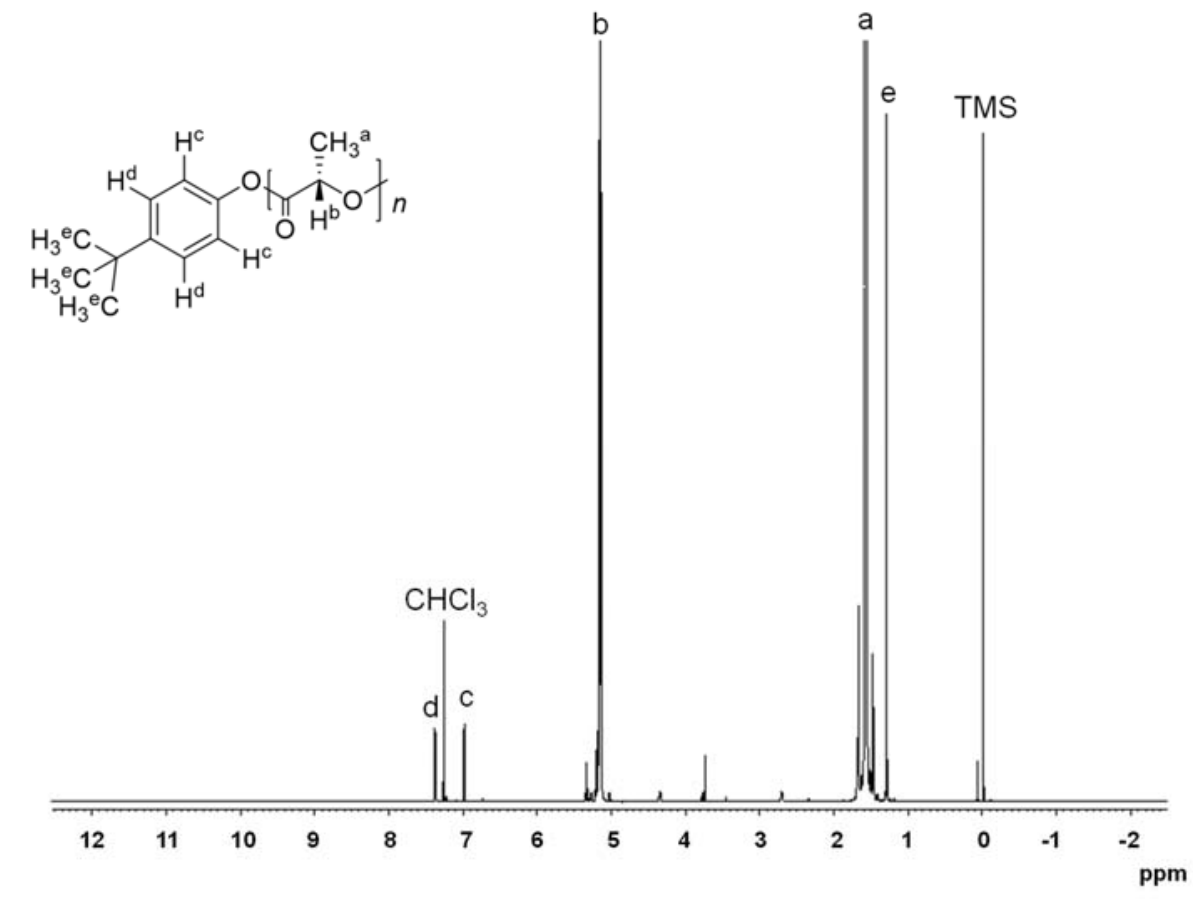

Figure S11. ${ }^{1} \mathrm{H}$ NMR spectrum of PLLA-4-tert-butylphenol (11) in $\mathrm{CDCl}_{3}(600 \mathrm{MHz})$.

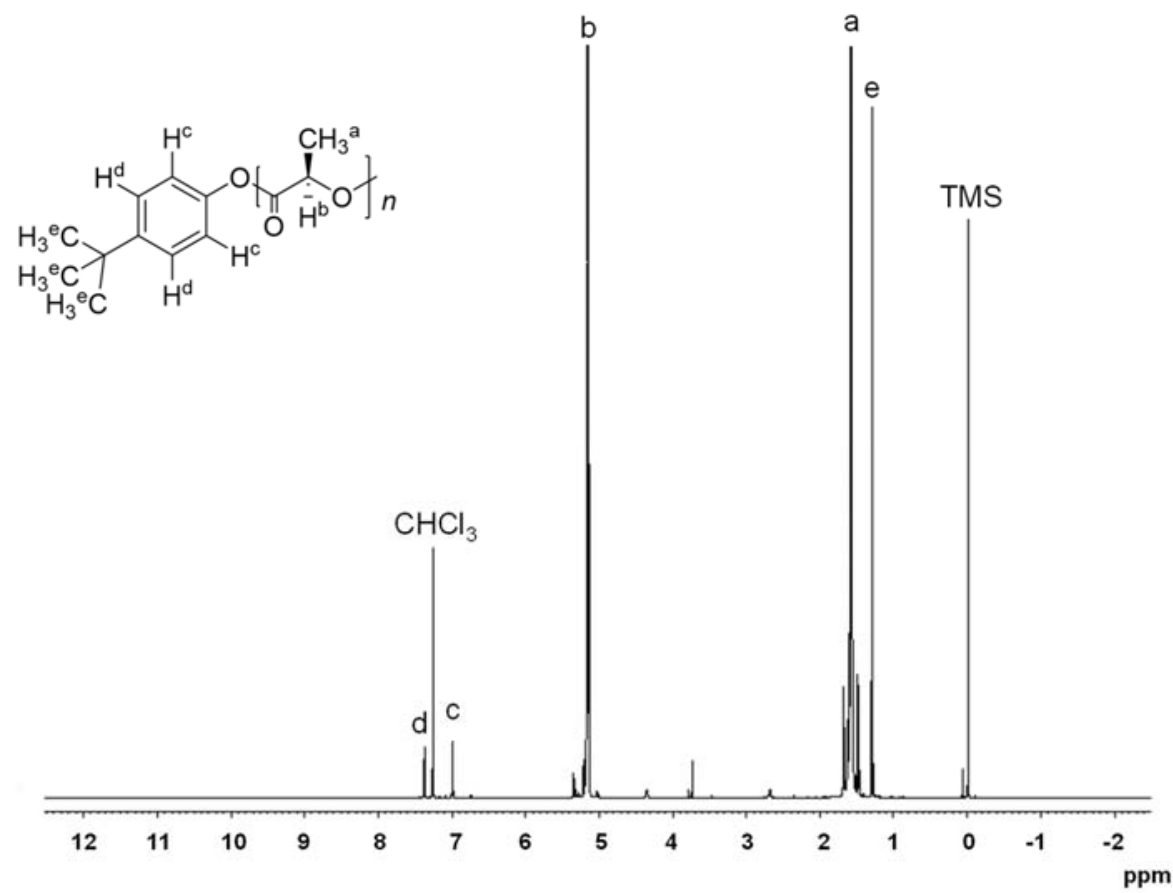

Figure S12. ${ }^{1} \mathrm{H}$ NMR spectrum of PDLA-4-tert-butylphenol (12) in $\mathrm{CDCl}_{3}(600 \mathrm{MHz})$. 


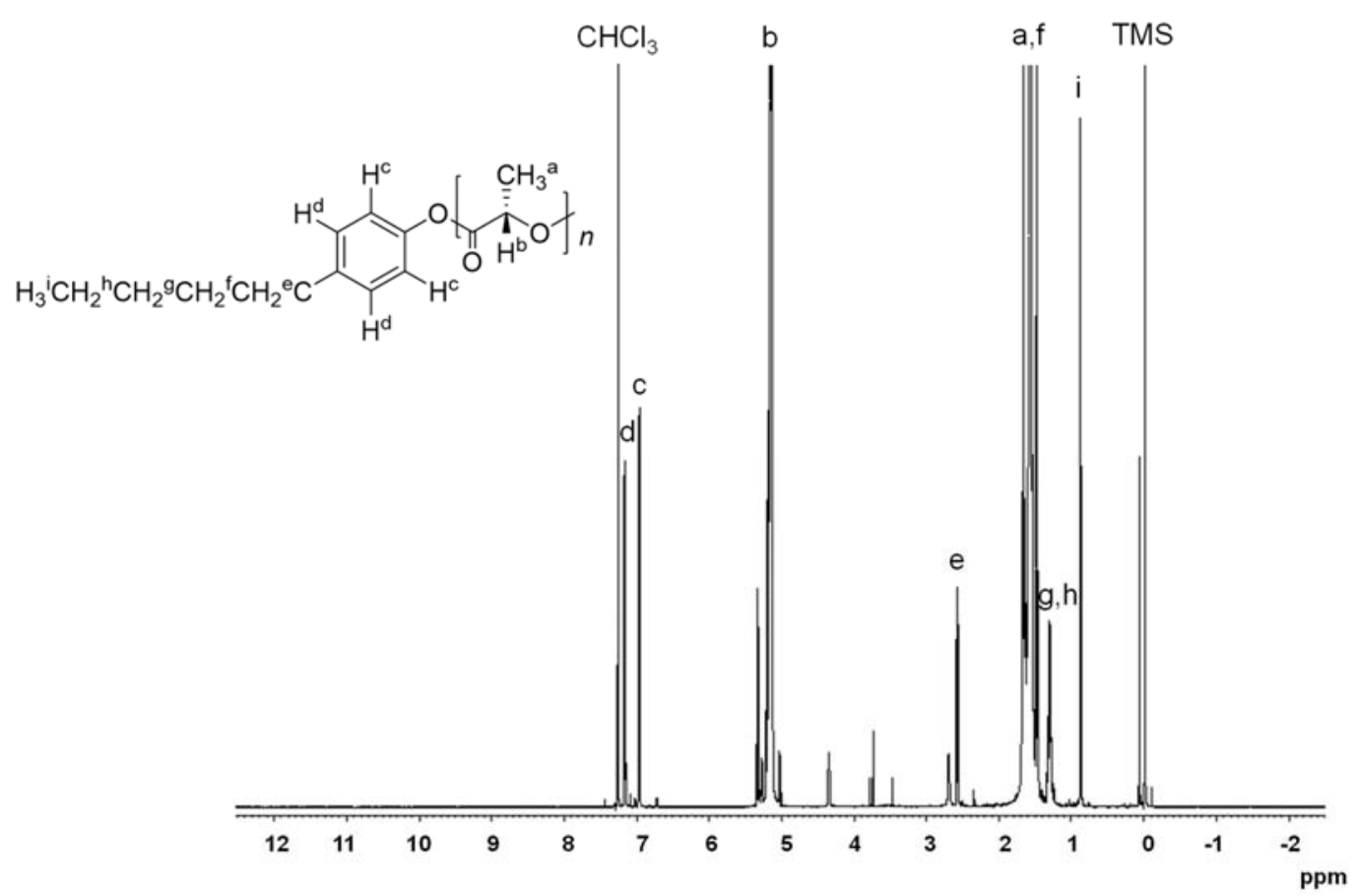

Figure S13. ${ }^{1} \mathrm{H}$ NMR spectrum of PLLA-4-amylphenol $(\mathbf{1 3})$ in $\mathrm{CDCl}_{3}(600 \mathrm{MHz})$.

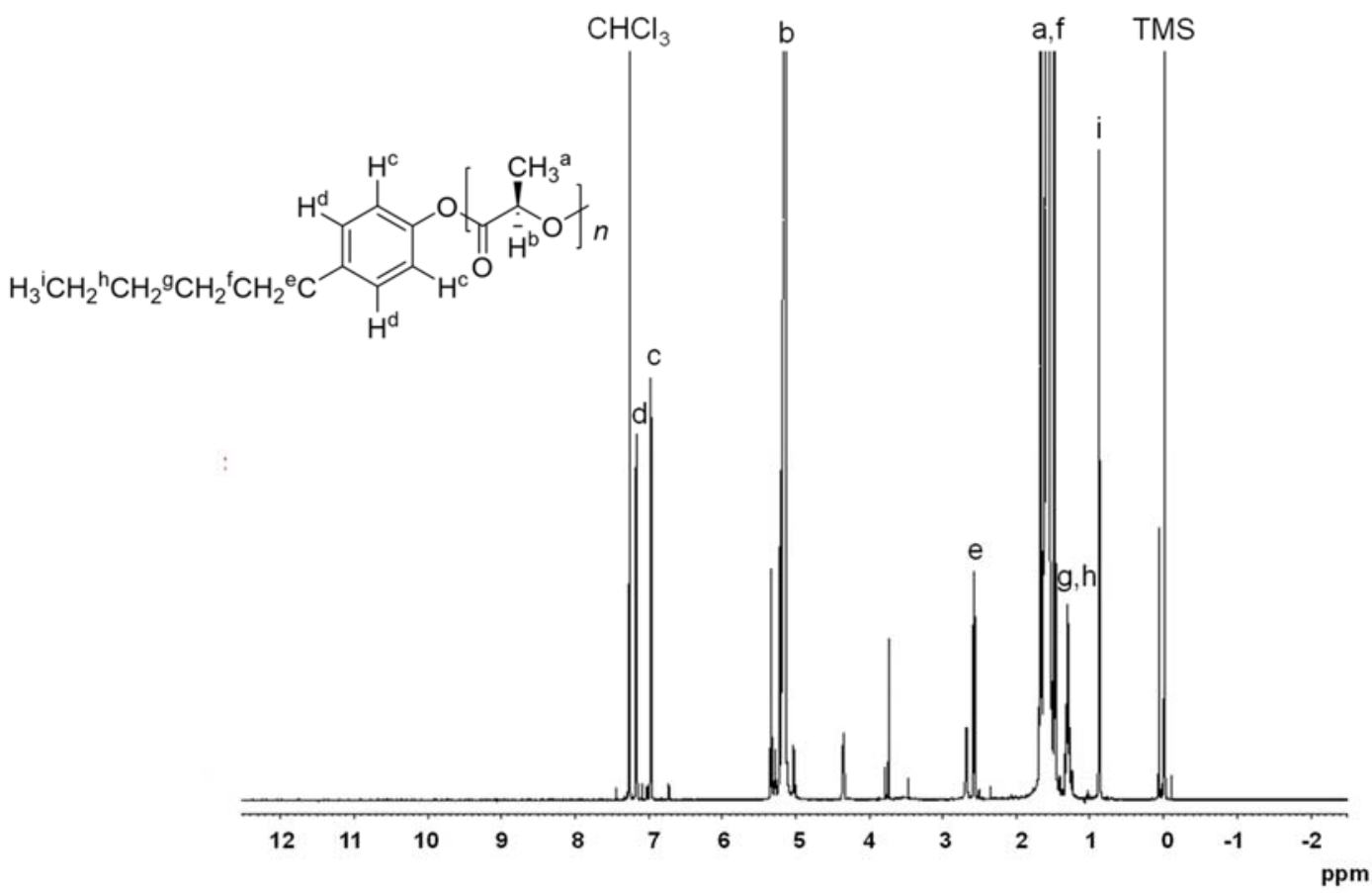

Figure S14. ${ }^{1} \mathrm{H}$ NMR spectrum of PDLA-4-amylphenol (14) in $\mathrm{CDCl}_{3}(600 \mathrm{MHz})$. 


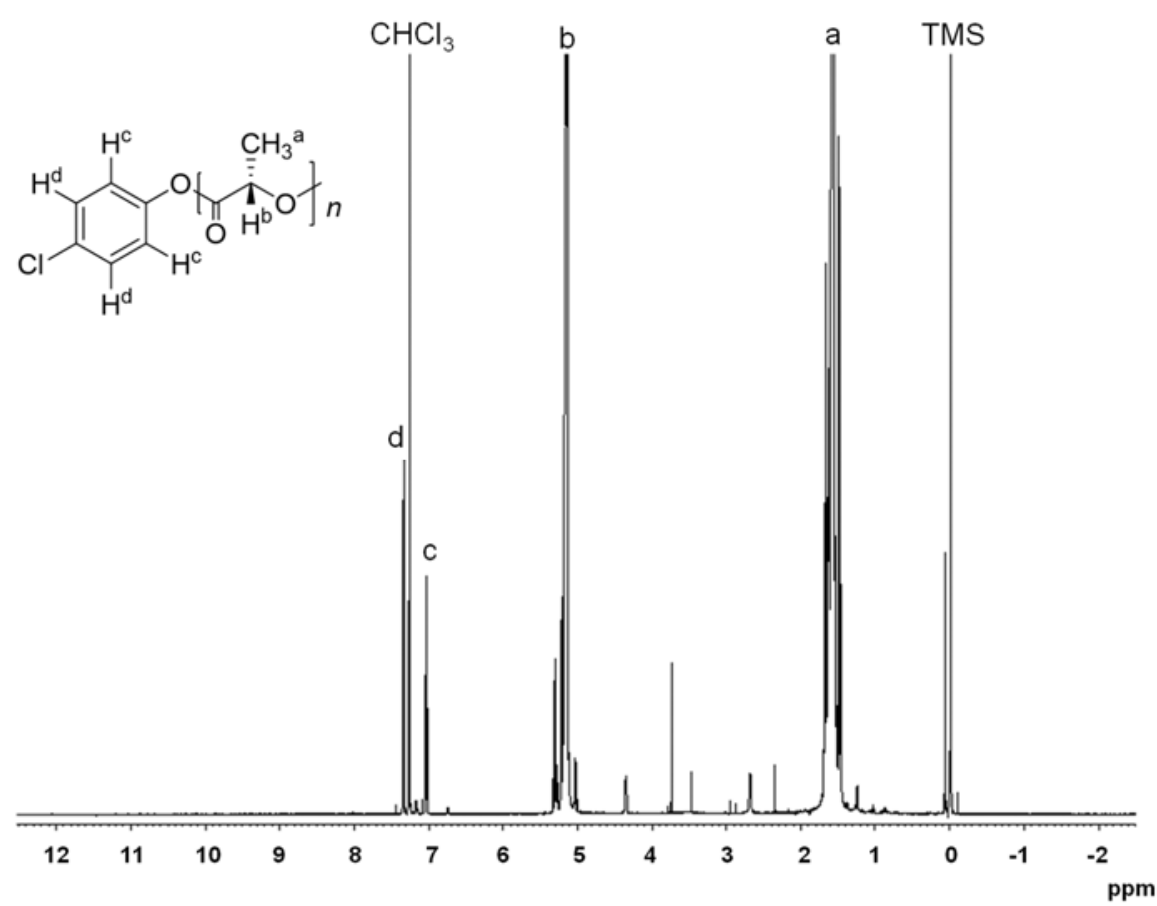

Figure S15. ${ }^{1} \mathrm{H}$ NMR spectrum of PLLA-4-chlorophenol (15) in $\mathrm{CDCl}_{3}(600 \mathrm{MHz})$.

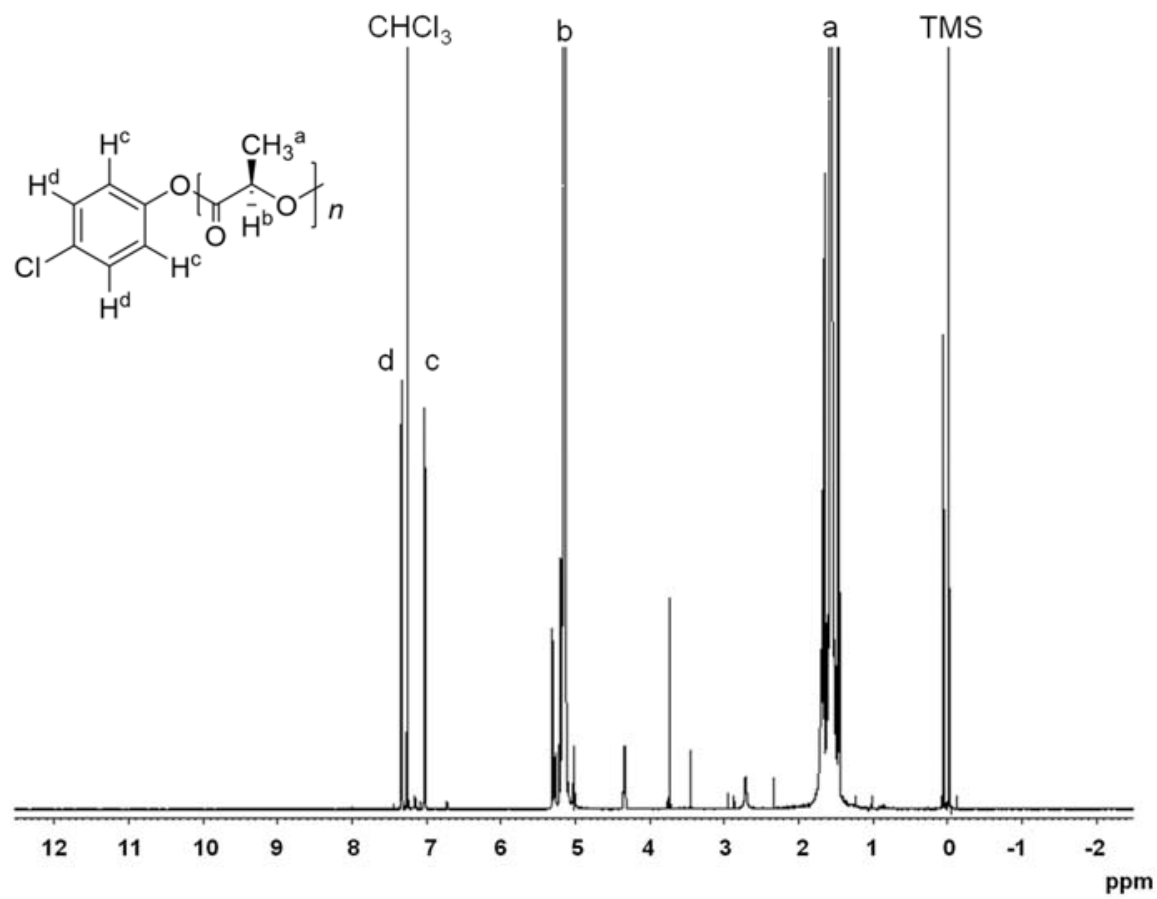

Figure S16. ${ }^{1} \mathrm{H}$ NMR spectrum of PDLA-4-chlorophenol (16) in $\mathrm{CDCl}_{3}(600 \mathrm{MHz})$. 


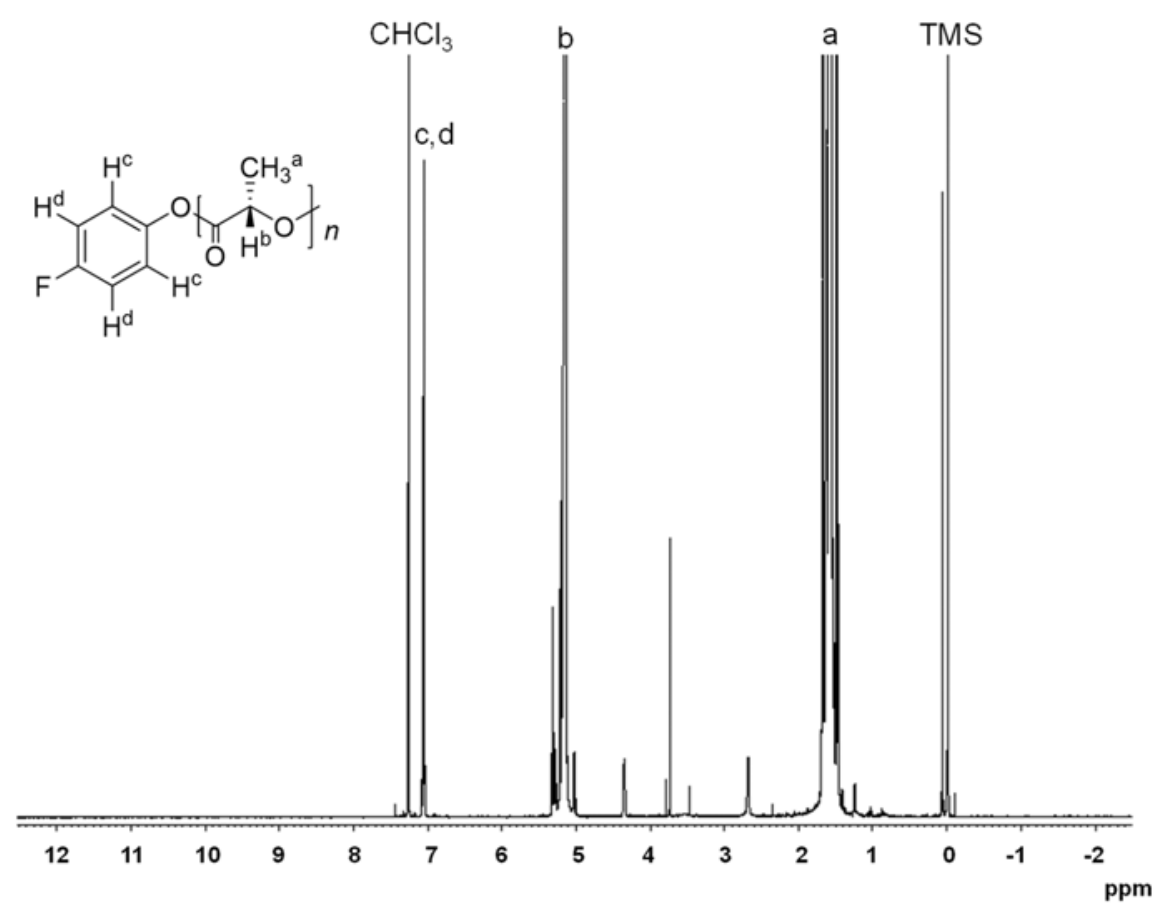

Figure S17. ${ }^{1} \mathrm{H}$ NMR spectrum of PLLA-4-fluorophenol (17) in $\mathrm{CDCl}_{3}(600 \mathrm{MHz})$.

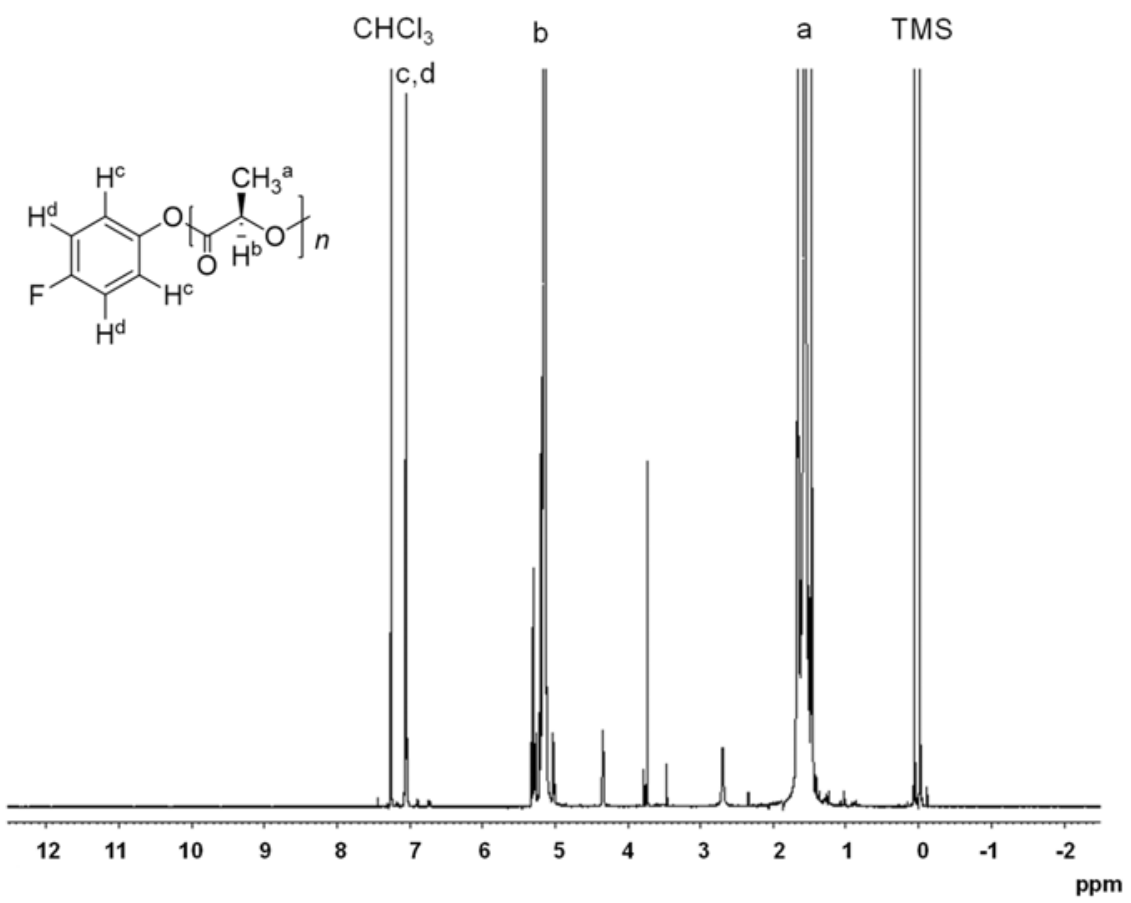

Figure S18. ${ }^{1} \mathrm{H}$ NMR spectrum of PDLA-4-fluorophenol (18) in $\mathrm{CDCl}_{3}(600 \mathrm{MHz})$. 


\section{CD and UV-vis spectra of polymers}

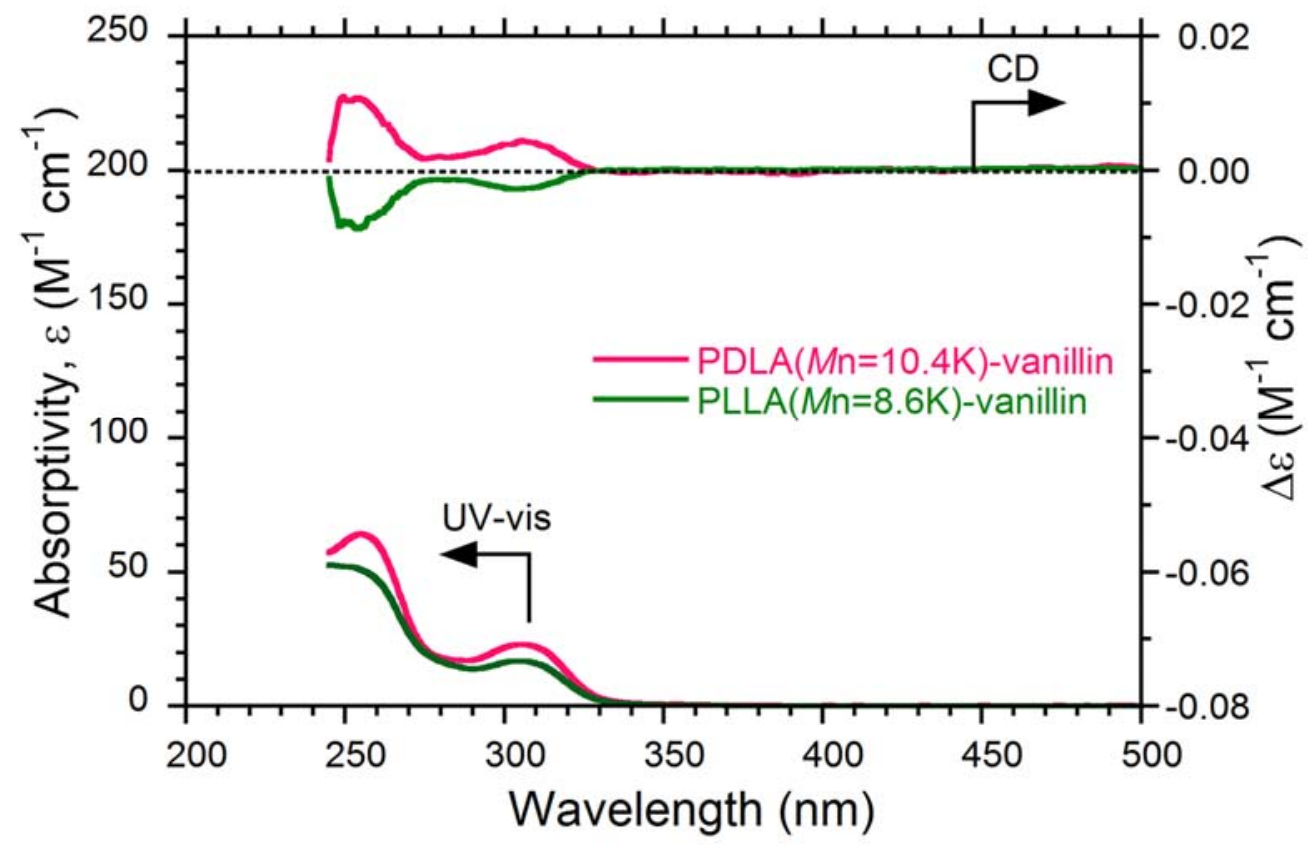

Figure S19. CD and UV-vis absorption spectra of the PLLA-vanillin (1a) and PDLA-vanillin (2a) in chloroform at $20^{\circ} \mathrm{C}$. Concentration of the solution is $0.050 \mathrm{~mol} \mathrm{~L}^{-1}$ in PLLA-vanillin (1a), and $0.025 \mathrm{~mol}$ $\mathrm{L}^{-1}$ in PDLA-vanillin (2a). 


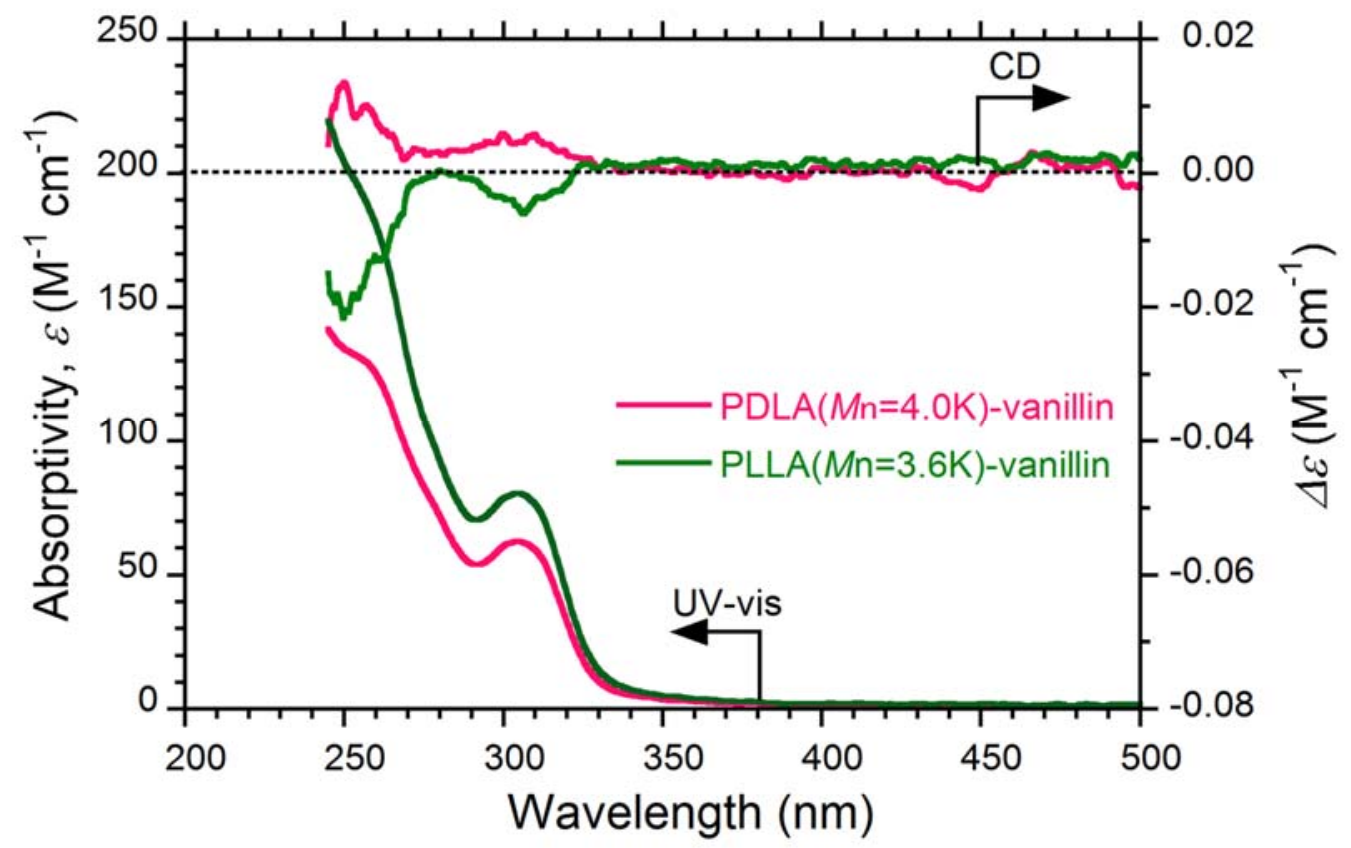

Figure S20. CD and UV-vis absorption spectra of the PLLA-vanillin (1b) and PDLA-vanillin (2b) in chloroform at $20{ }^{\circ} \mathrm{C}$. Concentration of the solution is $0.063 \mathrm{~mol} \mathrm{~L}^{-1}$ in PLLA-vanillin (1b) and PDLAvanillin (2b). 
(a)

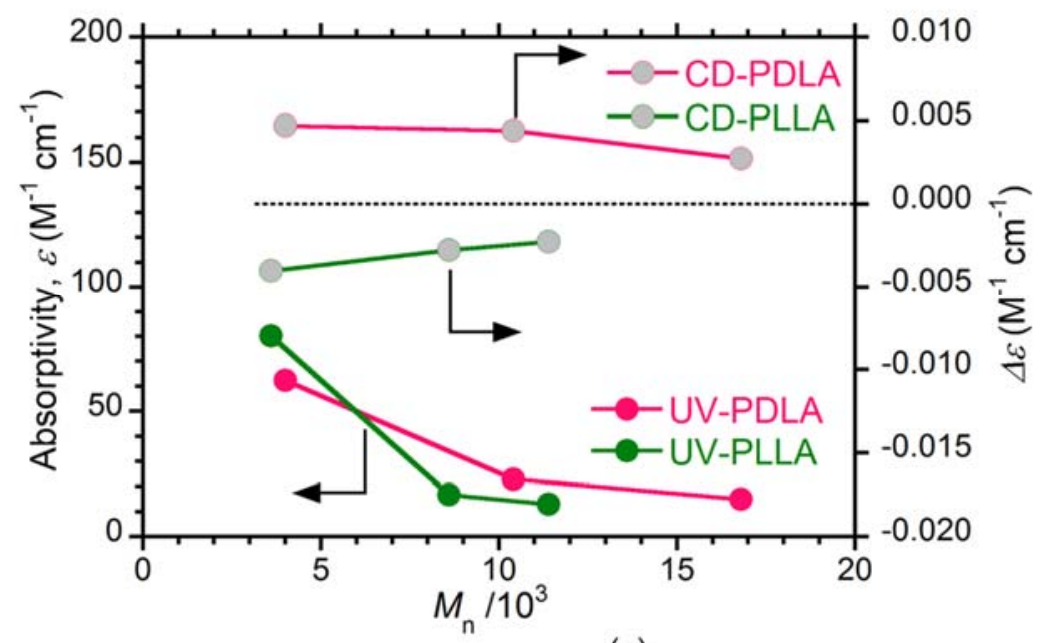

(b)

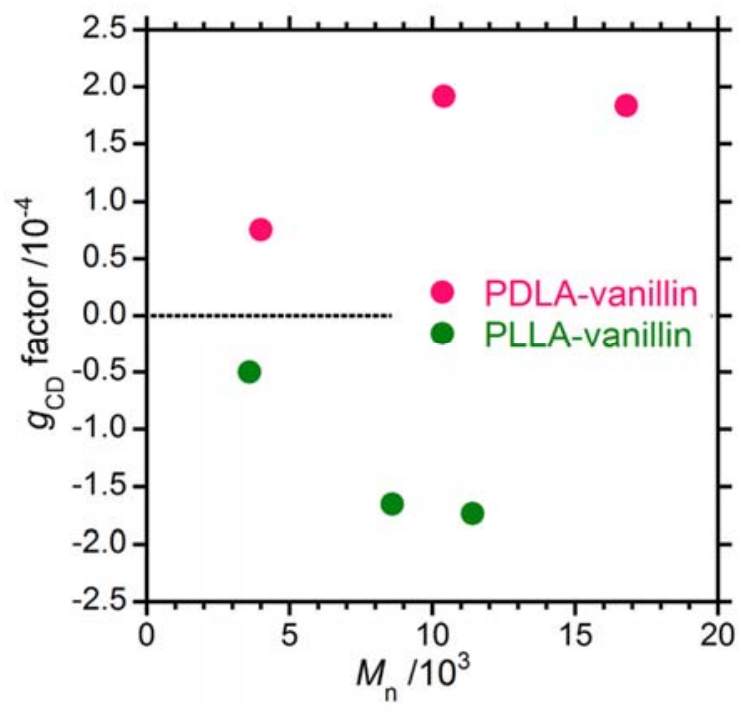

(c)

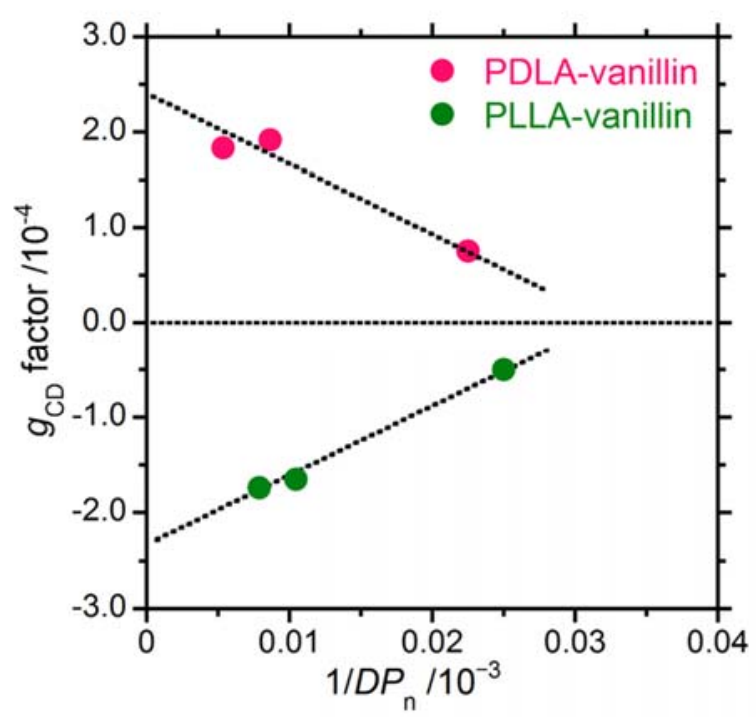

Figure S21. PLLA-vanillin and PDLA-vanillin in chloroform at $20{ }^{\circ} \mathrm{C}$ of (a) The absorptivity and ellipticity at the first Cotton band at $307 \mathrm{~nm}$ due to vanillin end terminus as a function of $M_{\mathrm{n}}$ (PDLA and PLLA bearing in chloroform at $20{ }^{\circ} \mathrm{C}$. (b) The $g_{\mathrm{CD}}$ values at the first Cotton band as a function of $M_{\mathrm{n}}$ in chloroform at $20{ }^{\circ} \mathrm{C}$. (c) The $g_{\mathrm{CD}}$ values at the first Cotton band as a function of reciprocal $D P_{\mathrm{n}}$ in chloroform at $20^{\circ} \mathrm{C}$. 


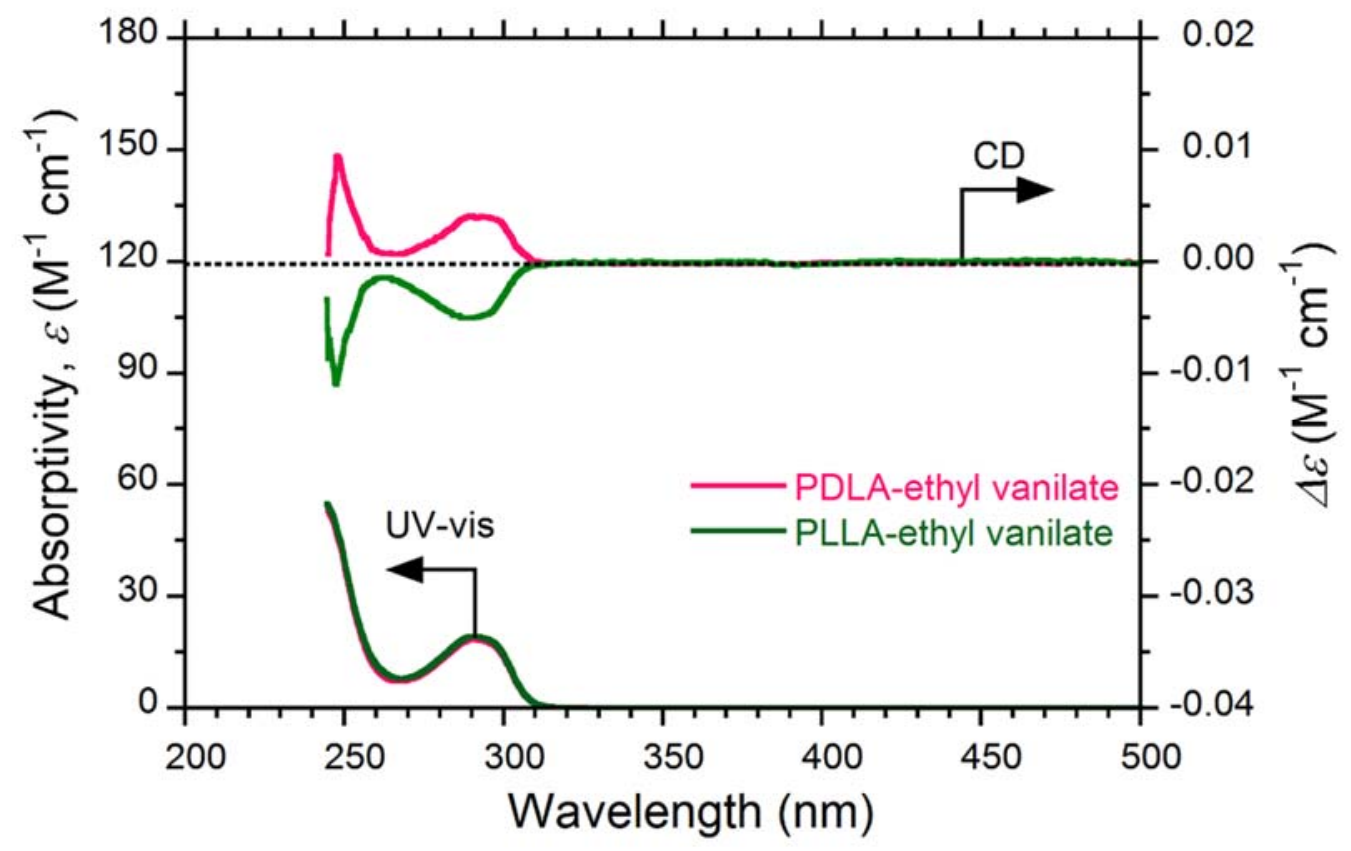

Figure S22. CD and UV-vis absorption spectra of the PLLA-ethyl vanilate (5) and PDLA-ethyl vanilate (6) in chloroform at $20^{\circ} \mathrm{C}$. Concentration of the solution is $0.050 \mathrm{~mol} \mathrm{~L}^{-1}$. 


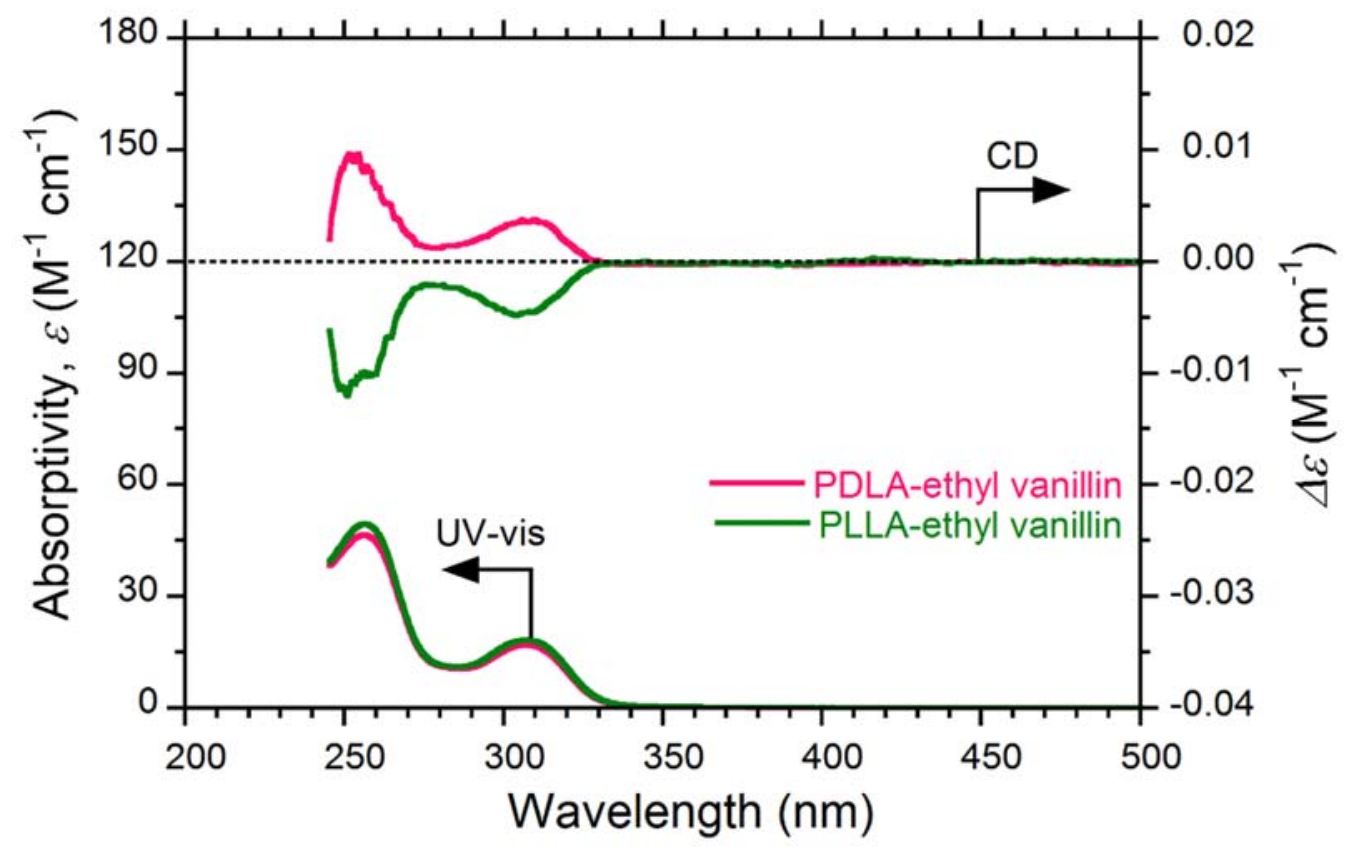

Figure S23. CD and UV-vis absorption spectra of the PLLA-ethyl vanillin (7) and PDLA-ethyl vanillin (8) in chloroform at $20^{\circ} \mathrm{C}$. Concentration of the solution is $0.050 \mathrm{~mol} \mathrm{~L}^{-1}$. 


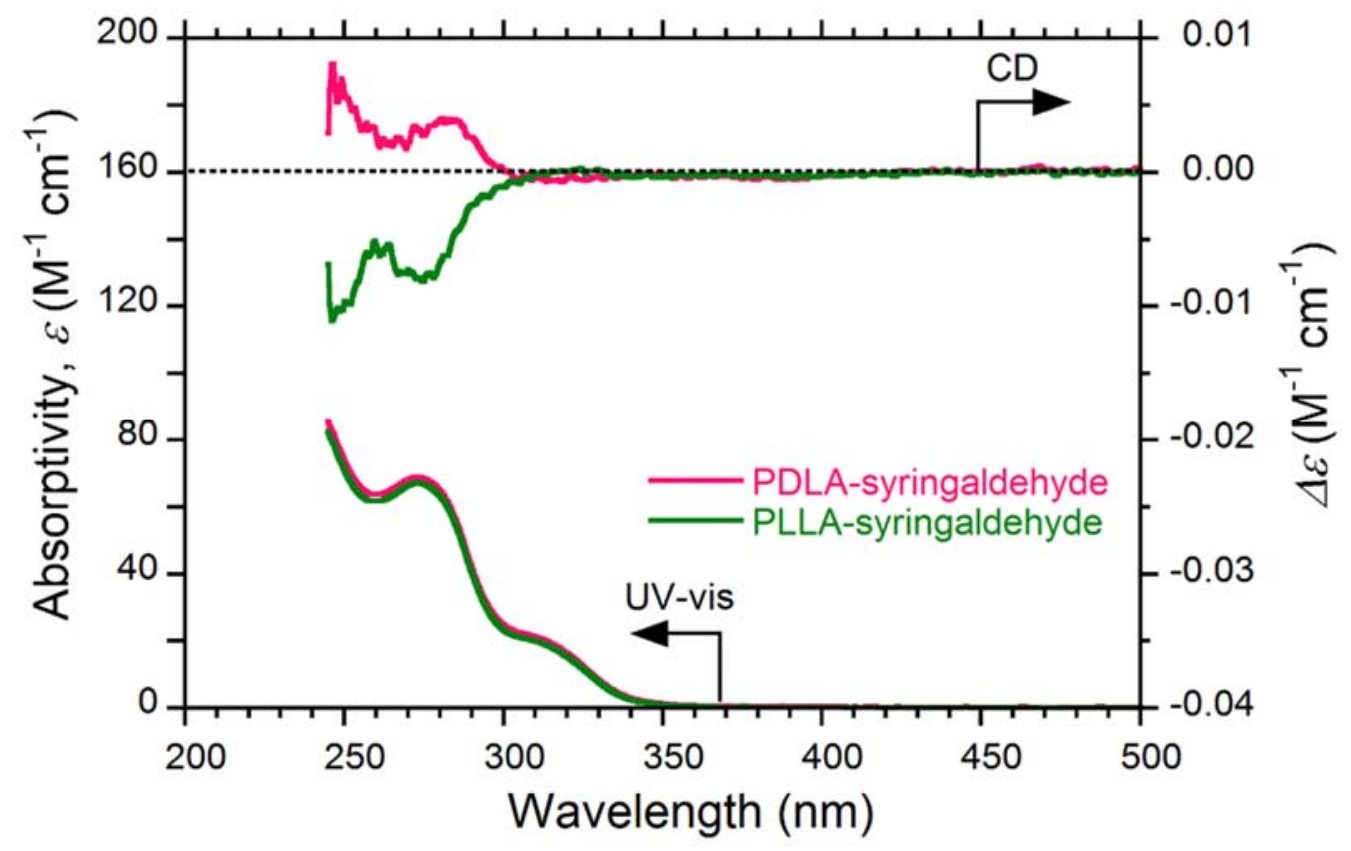

Figure S24. CD and UV-vis absorption spectra of the PLLA-syringaldehyde (9) and PDLAsyringaldehyde (10) in chloroform at $20^{\circ} \mathrm{C}$. Concentration of the solution is $0.025 \mathrm{~mol} \mathrm{~L}^{-1}$. 


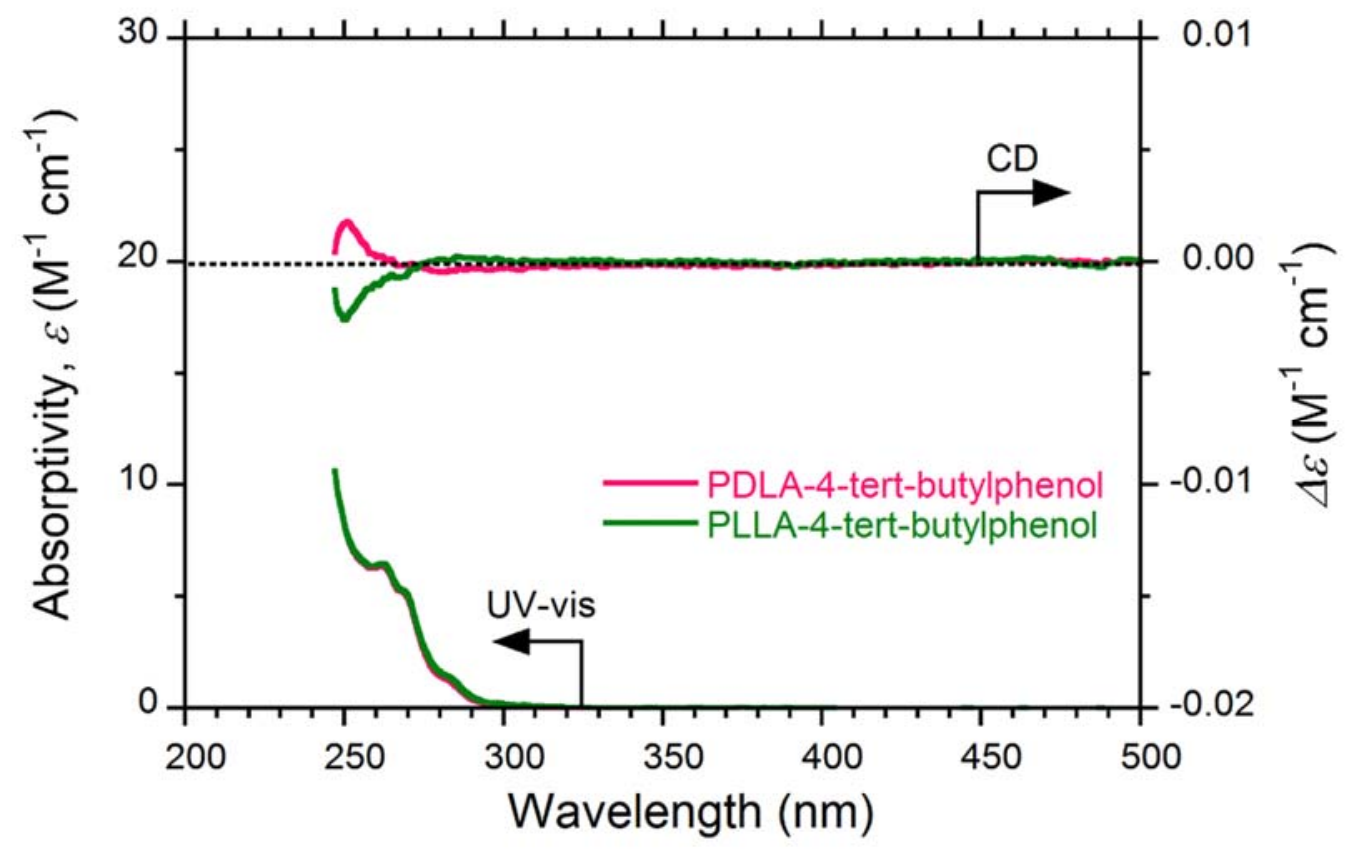

Figure S25. CD and UV-vis absorption spectra of the PLLA-4-tert-butylphenol (11) and PDLA-4-tertbutylphenol (12) in chloroform at $20^{\circ} \mathrm{C}$. Concentration of the solution is $0.050 \mathrm{~mol} \mathrm{~L}^{-1}$. 


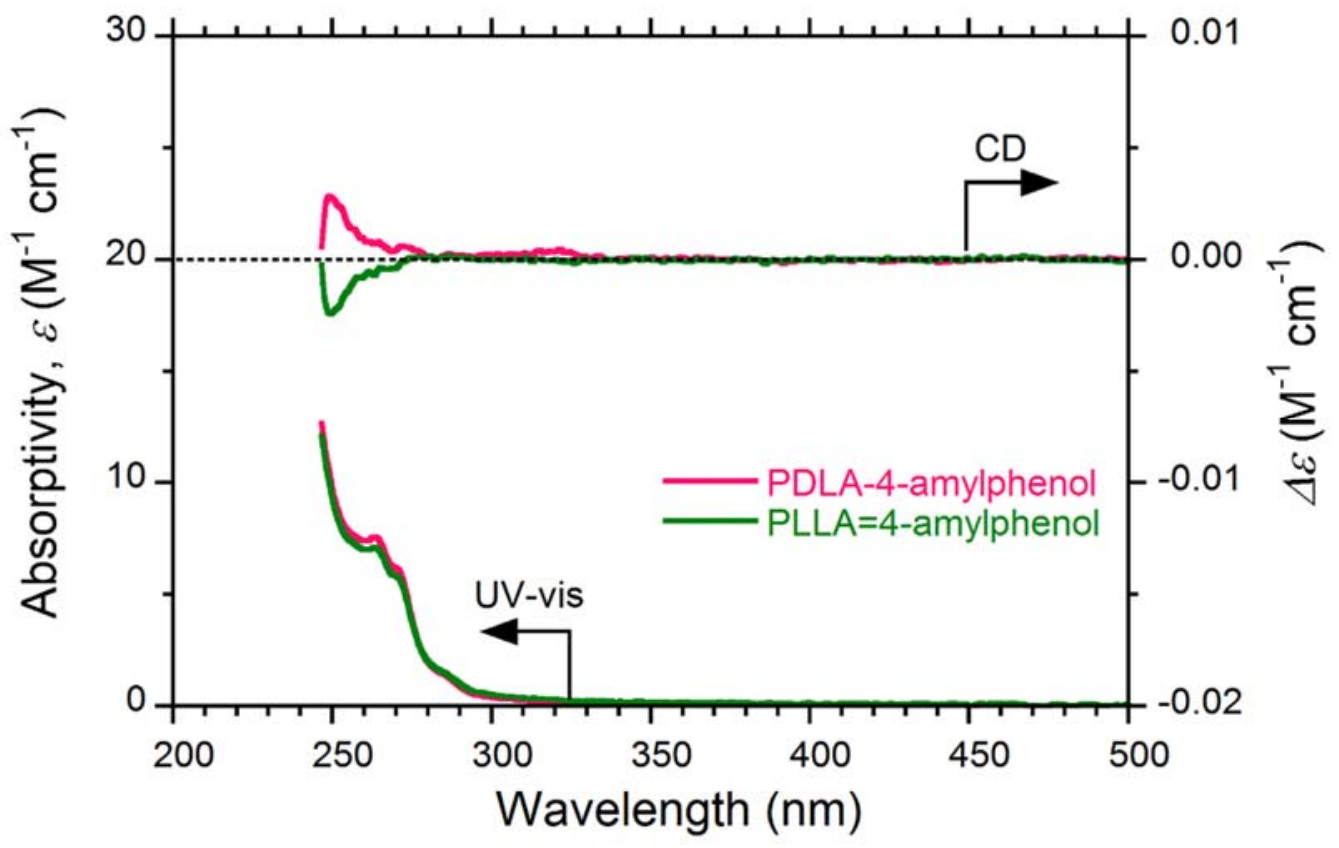

Figure S26. CD and UV-vis absorption spectra of the PLLA-4-amylphenol (13) and PDLA-4-amylphenol (14) in chloroform at $20^{\circ} \mathrm{C}$. Concentration of the solution is $0.050 \mathrm{~mol} \mathrm{~L}^{-1}$. 


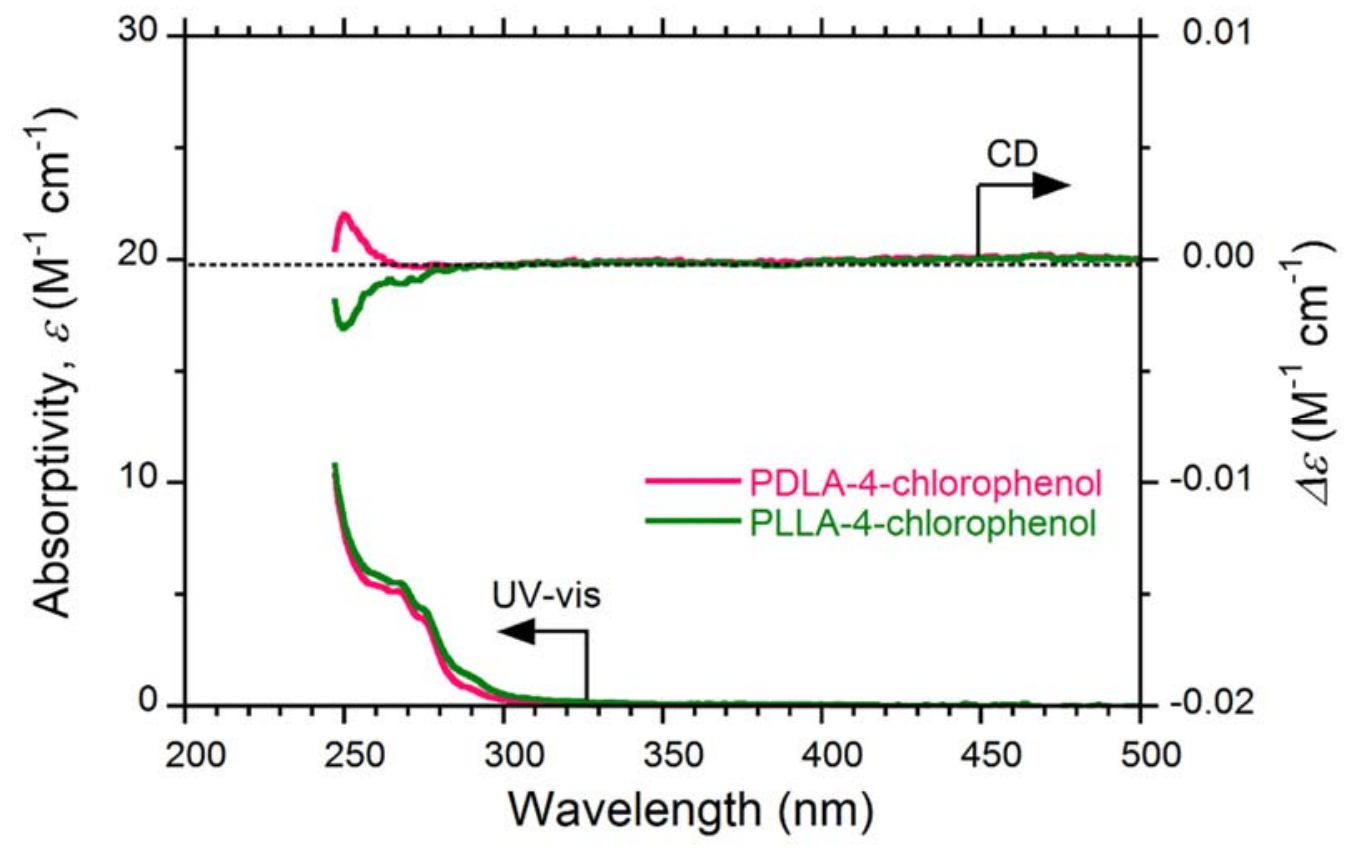

Figure S27. CD and UV-vis absorption spectra of the PLLA-4-chlorophenol (15) and PDLA-4chlorophenol (16) in chloroform at $20^{\circ} \mathrm{C}$. Concentration of the solution is $0.050 \mathrm{~mol} \mathrm{~L}^{-1}$. 


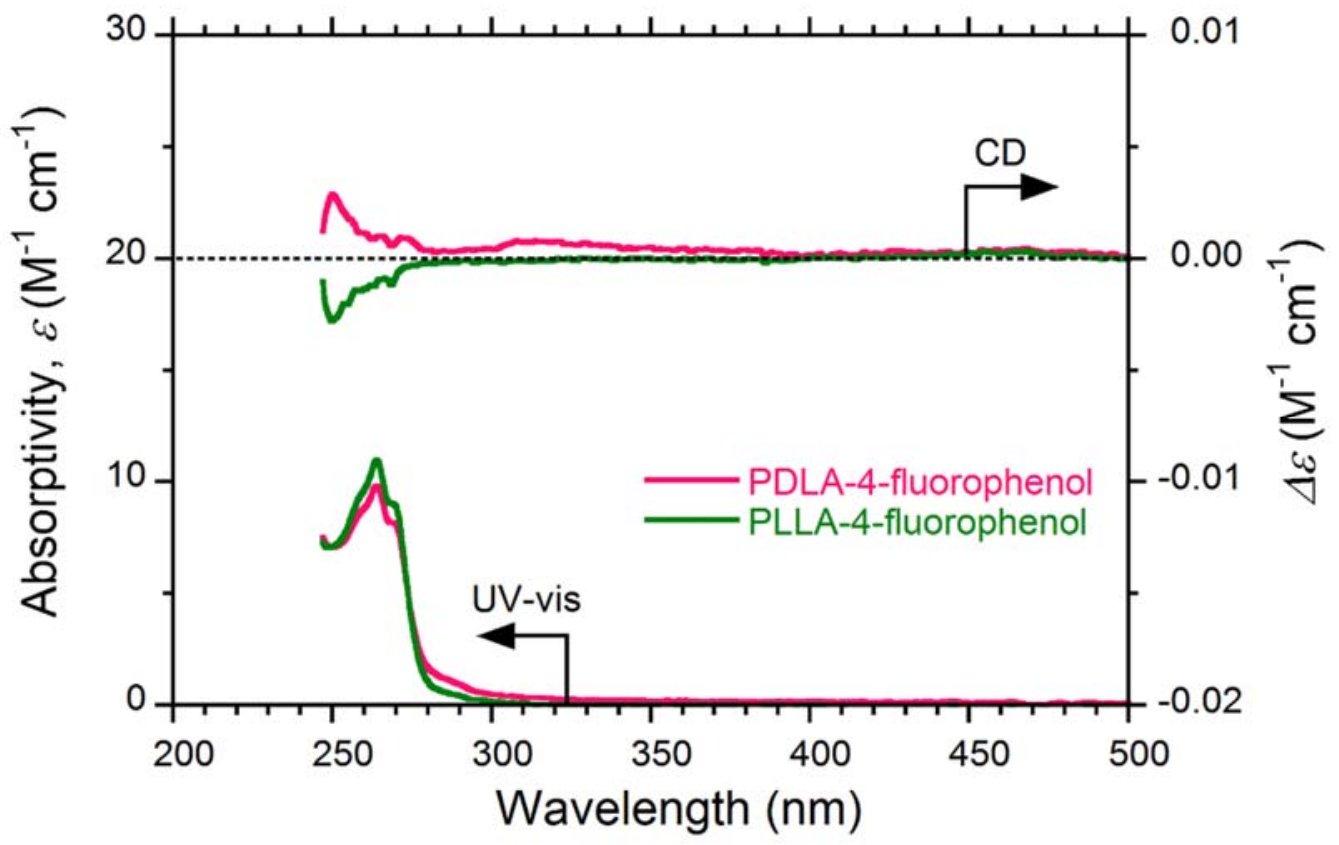

Figure S28. CD and UV-vis absorption spectra of the PLLA-4-fluorophenol (17) and PDLA-4fluorophenol (18) in chloroform at $20^{\circ} \mathrm{C}$. Concentration of the solution is $0.050 \mathrm{~mol} \mathrm{~L}^{-1}$. 


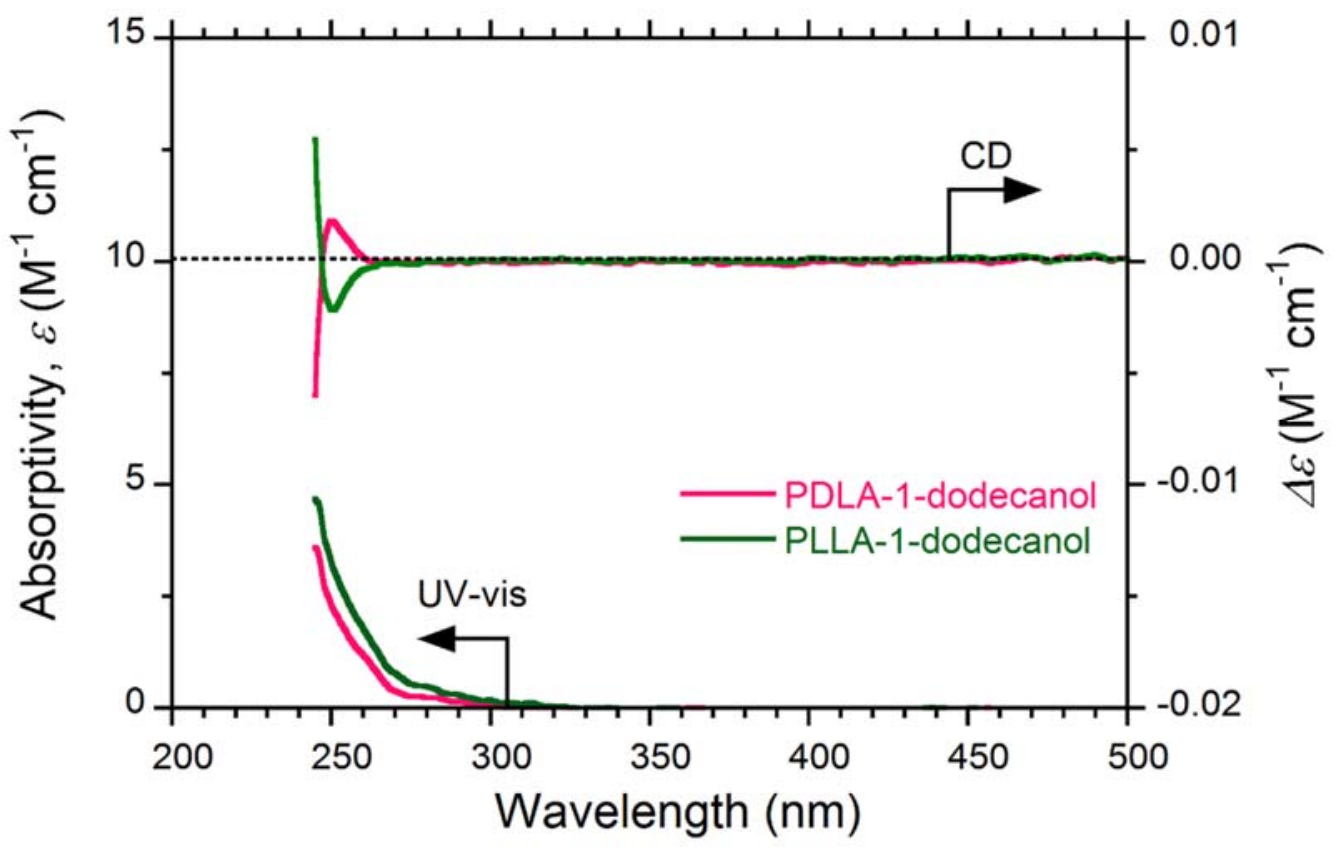

Figure S29. CD and UV-vis absorption spectra of the PLLA-1-dodecanol (19) and PDLA-1-dodecanol (20) in chloroform at $20^{\circ} \mathrm{C}$. Concentration of the solution is $0.050 \mathrm{~mol} \mathrm{~L}^{-1}$. 


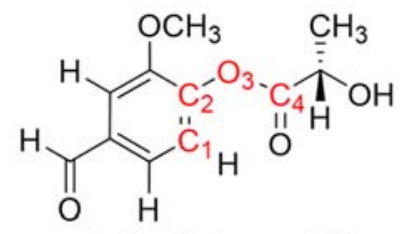

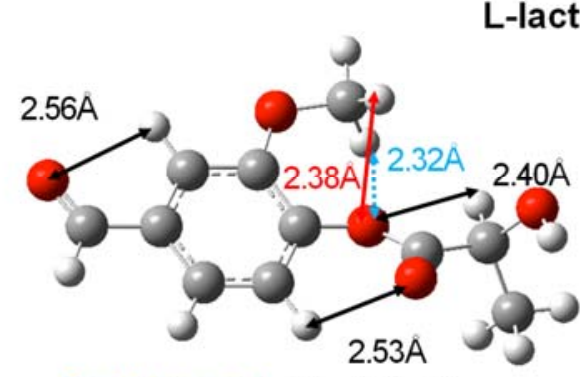

Conformer $\mathrm{A}$ at $-40^{\circ}$ of dihedral angle $\left(\mathrm{C}_{1}-\mathrm{C}_{2}-\mathrm{O}_{3}-\mathrm{C}_{4}\right)$

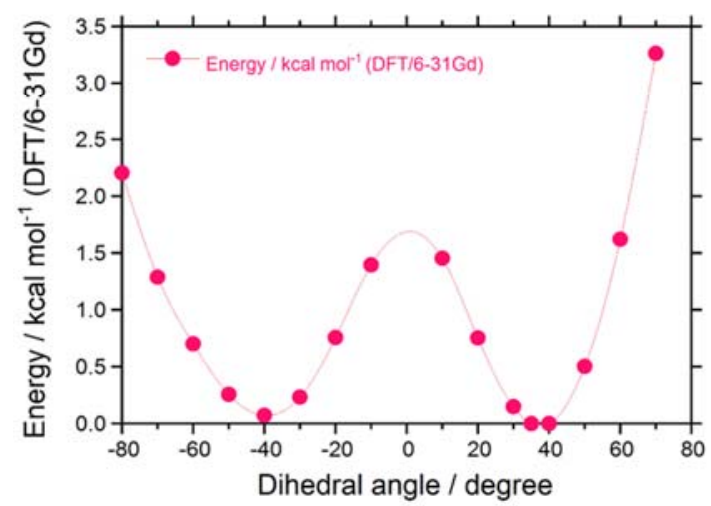

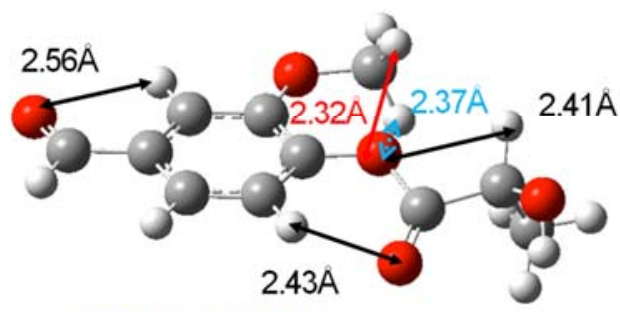

Conformer B at $+40^{\circ}$ of dihedral angle $\left(\mathrm{C}_{1}-\mathrm{C}_{2}-\mathrm{O}_{3}-\mathrm{C}_{4}\right)$

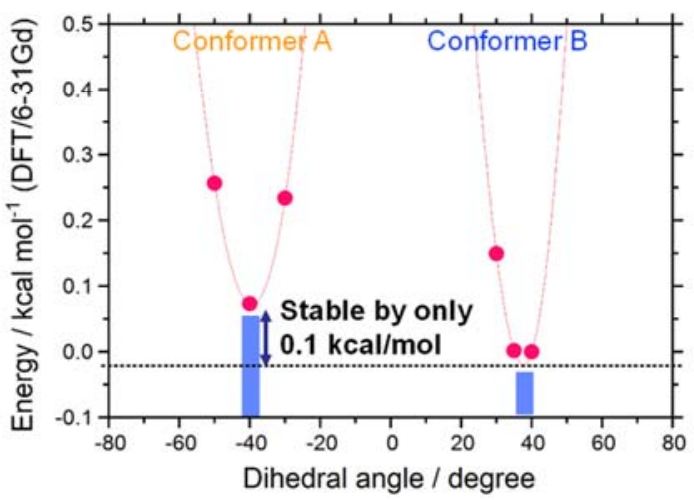

Figure S30. (Top). The model structure of L-lactide-vanillin for calculation (TD-DFT, B3LYP/6-31G(d) basis set). (Middle, left) Conformer A of L-lactide and benzene ring of vanillin as a function of dihedral angle $\left(\mathrm{C}_{1}-\mathrm{C}_{2}-\mathrm{O}_{3}-\mathrm{C}_{4}\right)$ at $-40^{\circ}$. (Middle, right) Conformer $\mathrm{B}$ of L-lactide and benzene ring of vanillin as a function of dihedral angle $\left(\mathrm{C}_{1}-\mathrm{C}_{2}-\mathrm{O}_{3}-\mathrm{C}_{4}\right)$ at $40^{\circ}$. Noting that $\mathrm{C}-\mathrm{H} / \mathrm{O}$ distance led by Bondi is $2.72 \AA$, when $\mathrm{C}-\mathrm{H} / \mathrm{O}$ interaction was absent. (Bottom, left) Potential energy surface of L-lactide and benzene ring of vanillin as a function of dihedral angle with $10^{\circ}$. (Bottom, right) Magnified y axis of the bottom left Figure of potential energy surface. The energy difference between conformers A and B was $0.1 \mathrm{kcal}$ $\mathrm{mol}^{-1}$. 
(a)

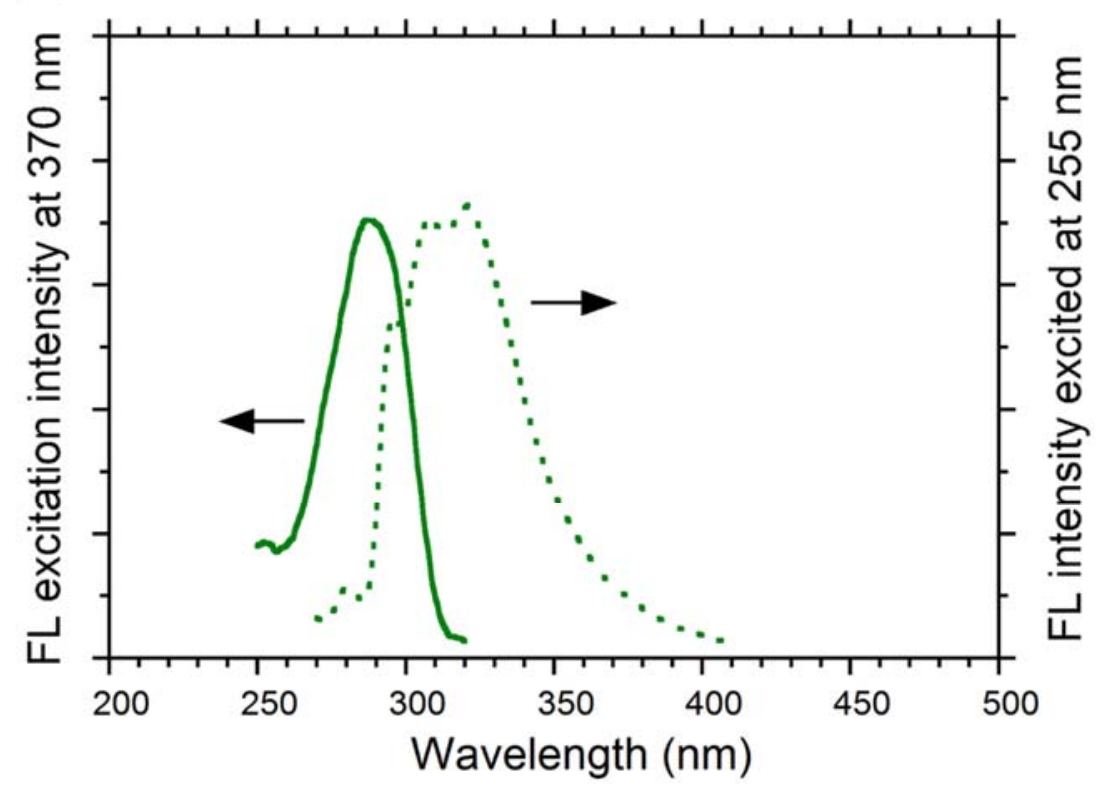

(b)

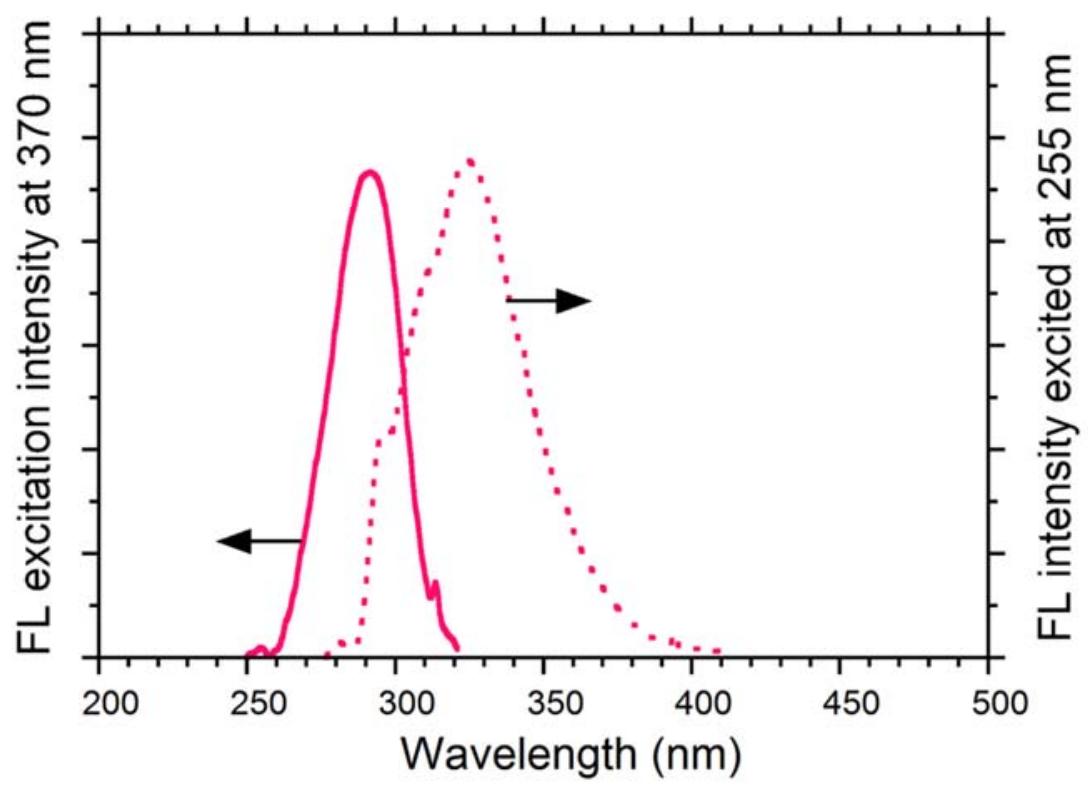

Figure S31. Fluorescent (excited at $255 \mathrm{~nm}$ ) and the corresponding fluorescent excitation (monitored at $370 \mathrm{~nm}$ ) spectra of (a) PLLA-vanillin (1) and (b) PDLA-vanillin (2) in $\mathrm{CHCl}_{3}$ (chloroform, super dehydrated, amylene added). [repeating unit] $=0.020 \mathrm{~mol} \mathrm{~L}^{-1}$. 


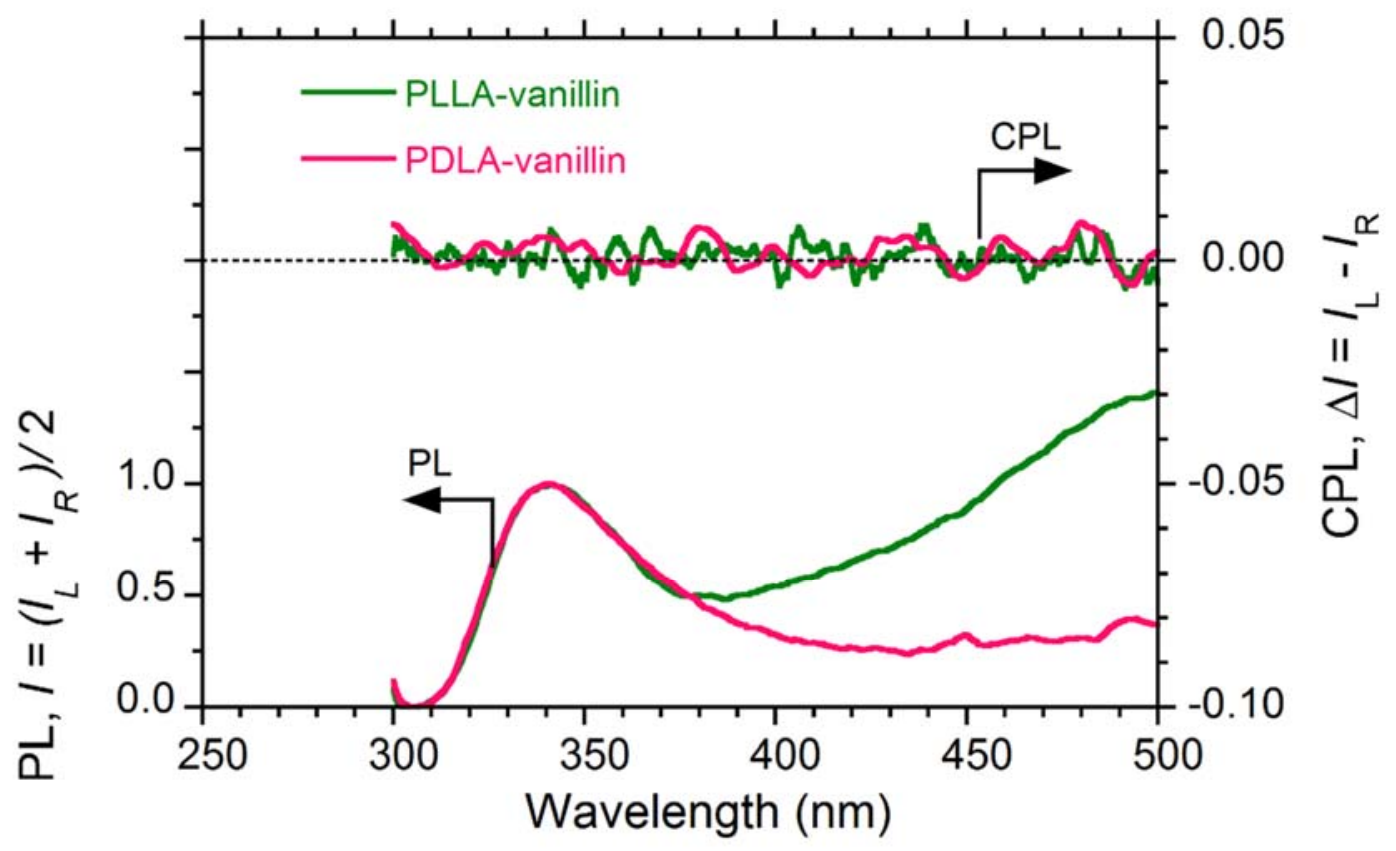

Figure S32. CPL and PL spectra of PLLA-vanillin (1) and PDLA-vanillin (2) in $\mathrm{CHCl}_{3}$ (Wako, spectroscopic-grade chloroform, super dehydrated, amylene added). [repeating unit] $=0.10 \mathrm{~mol} \mathrm{~L}^{-1} \cdot \lambda_{\mathrm{ex}}=$ $280 \mathrm{~nm}$.

\section{REFERENCE}

[S1] Frisch, M. J.; Trucks, G. W.; Schlegel, H. B.; Scuseria, G. E.; Robb, M. A.; Cheeseman, J. R.; Scalmani, G.; Barone, V.; Mennucci, B.; Petersson, G. A.; Nakatsuji, H.; Caricato, M.; Li, X.; Hratchian, H. P.; Izmaylov, A. F.; Bloino, J.; Zheng, G.; Sonnenberg, J. L.; Hada, M.; Ehara, M.; Toyota, K.; Fu-kuda, R.; Hasegawa, J.; Ishida, M.; Nakajima, T.; Honda, Y.; Kitao, O.; Nakai, H.; Vreven, T.; Montgomery, J. A. Jr.; Peralta, J. E.; Ogliaro, F.; Bearpark, M.; Heyd, J. J.; Brothers, E.; Kudin, K. N.; Staroverov, V. N.; Keith, T.; Kobayashi, R.; Normand, J.; Raghavachari, K.; Rendell, A.; Burant, J. C.; Iyengar, S. S.; Tomasi, J.; Cossi, M.; Rega, N.; Millam, J. M.; Klene, M.; Knox, J. E.; Cross, J. B.; Bakken, V.; Adamo, C.; Jaramillo, J.; Gomperts, R.; Stratmann, R. E.; Yazyev, O.; Austin, A. J.; Cammi, R.; Pomelli, C.; Ochterski, J. W.; Martin, R. L.; Morokuma, K.; Zakrzewski, V. G.; Voth, G. A.; Salvador, P.; Dannenberg, J. J.; Dapprich, S.; Daniels, A. D.; Farkas, O.; Foresman, J. B.; Ortiz, J. V.; Cioslowski, J.; Fox, D. J. Gaussian 09, Revision E.01; Gaussian, Inc.: Wallingford CT, 2013. 